\title{
Progressive Collapse of Exterior Reinforced Concrete Beam-Column Sub-assemblages: Considering the Effects of a Transverse Frame
}

\author{
Omid Rashidian ${ }^{1), *}$, Reza Abbasnia ${ }^{1)}$, Rasool Ahmadi ${ }^{2}$, and Foad Mohajeri Nav ${ }^{1)}$
}

(Received February 21, 2016, Accepted July 30, 2016, Published online August 23, 2016)

\begin{abstract}
Many experimental studies have evaluated the in-plane behavior of reinforced concrete frames in order to understand mechanisms that resist progressive collapse. The effects of transverse beams, frames and slabs often are neglected due to their probable complexities. In the present study, an experimental and numerical assessment is performed to investigate the effects of transverse beams on the collapse behavior of reinforced concrete frames. Tests were undertaken on a 3/10-scale reinforced concrete sub-assemblage, consisting of a double-span beam and two end columns within the frame plane connected to a transverse frame at the middle joint. The specimen was placed under a monotonic vertical load to simulate the progressive collapse of the frame. Alternative load paths, mechanism of formation and development of cracks and major resistance mechanisms were compared with a two-dimensional scaled specimen without a transverse beam. The results demonstrate a general enhancement in resistance mechanisms with a considerable emphasis on the flexural capacity of the transverse beam. Additionally, the role of the transverse beam in restraining the rotation of the middle joint was evident, which in turn leads to more ductile behavior. A macro-model was also developed to further investigate progressive collapse in three dimensions. Along with the validated numerical model, a parametric study was undertaken to investigate the effects of the removed column location and beam section details on the progressive collapse behavior.
\end{abstract}

Keywords: progressive collapse, reinforced concrete beams, experiment, alternative load path, finite element analysis.

\section{Introduction}

The progressive collapse of structures due to natural and manmade disasters has been the main focus of many recent studies. For example, Sasani et al. (2007, 2008a, b, 2011a, b) made great efforts to investigate the collapse behavior of full-scale reinforced concrete (RC) structures. In all of these cases, compressive arch action in beams, Vierendeel action in beams and columns, and also catenary action in longitudinal reinforcements were identified as the main resistance mechanisms against progressive collapse. Yi et al. (2008) performed laboratory tests on an $\mathrm{RC}$ planar frame in which the static responses were examined under progressive collapse.

In many studies, in scenarios in which the middle column was removed, the structural responses of RC sub-assemblages, including double beams and triple columns, were considered as a basis for estimating the resistance of real structures. Su et al. (2009) evaluated the load-carrying capacity of RC sub-assemblages against progressive collapse. They tested 12 reduced-scale specimens where the

\footnotetext{
${ }^{1)}$ Civil Engineering Department, Iran University of Science and Technology, Tehran, Iran.

*Corresponding Author;

E-mail: omidrashidian@iust.ac.ir

${ }^{2)}$ Building and House Research Centre, Tehran, Iran.

Copyright $($ The Author(s) 2016. This article is published with open access at Springerlink.com
}

beams were restrained longitudinally against axial deformation. The results indicated that compressive arch actions due to longitudinal restraint can significantly enhance the loadcarrying capacity of the beams. Sasani and Kropelnicki (2008) studied the behavior of a 3/8-scaled model of a continuous perimeter beam in a reinforced concrete frame structure following the removal of a supporting column. An experiment by Lew et al. (2011) examined the behavior of two full-scale RC sub-assemblages subjected to static loading under a middle column removal scenario. As with previous research, the resistance of sub-assemblages was based on arching and catenary actions. Yu and Tan (2011, 2013a, b) performed an experimental test on eight half-scale RC subassemblages under a middle column removal scenario.

$\mathrm{Yu}$ and Tan (2014) also proposed special detailing techniques for RC sub-assemblages to improve structural resistance under the column removal scenario. Tsai and Huang (2015) tested the collapse resistance of six reinforced concrete sub-assemblages designed with different span-to-depth ratios and varied stirrup spacings under gravitational loading. Farhang Vesali et al. (2013), Choi and Kim (2011) and Kim and Choi (2015) presented other notable studies that focused on the collapse behavior of RC sub-assemblages. Qian et al. (2014) investigated the contribution of secondary load-carrying mechanism, including transverse beams and membrane action of the slabs in RC assemblies. Qian et al. (2015) studied the three-dimensional (3D) effects on the progressive collapse behavior of RC frames. In addition to 


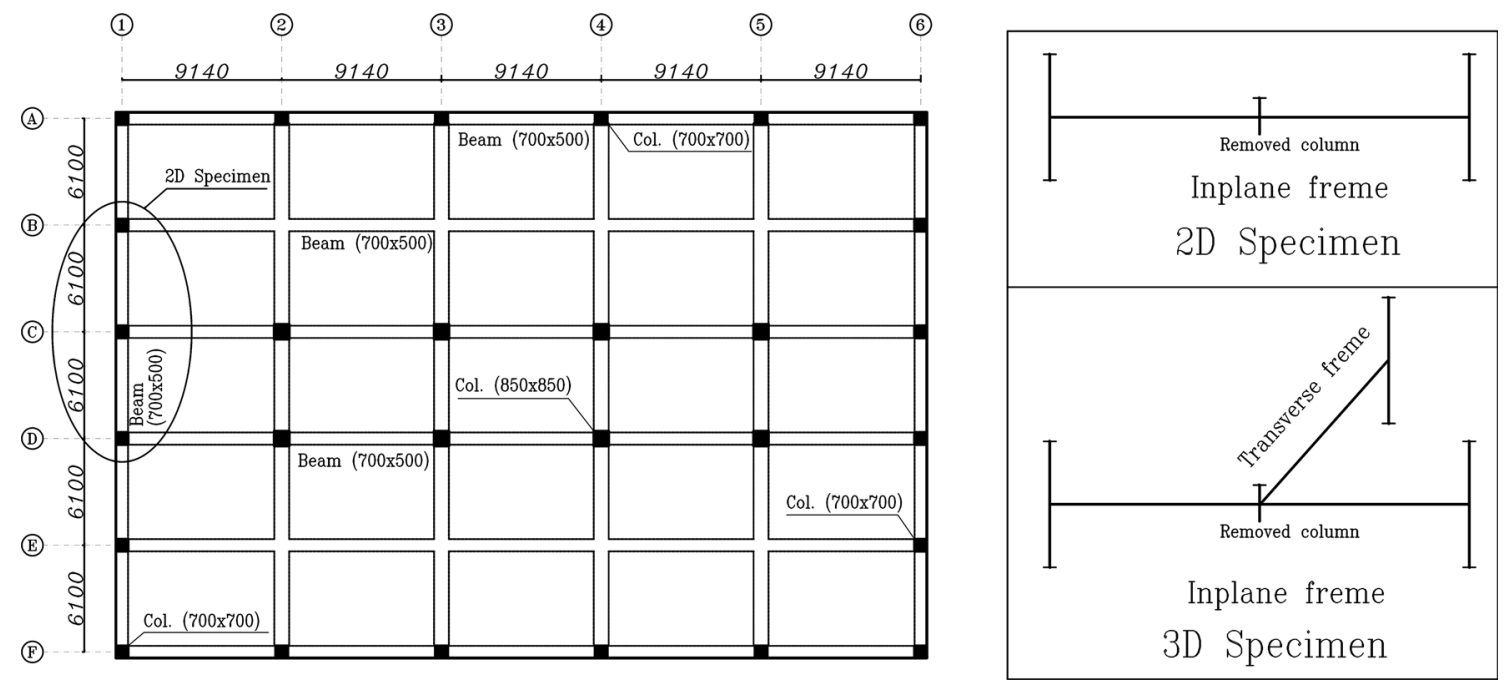

Fig. 1 Prototype building and selected specimens.

middle beam-column assemblies, extensive research by Qian and Li (2012a, b, 2015) investigated the behavior of $\mathrm{RC}$ frames under the loss of a corner column and quantified slab effects on the dynamic performance of RC frame subjected to the loss of column scenario.

In addition to experimental studies, other research has focused on analytical evaluations of RC sub-assemblages. Bao et al. (2014) performed a computational investigation of the middle beam-column assemblies and developed two types of models: detailed and reduced models. Bao et al. (2008) and Bao and Kunnath (2010) developed macromodel approaches to study the progressive collapse behavior of RC assemblies. Sasani et al. (2011b) introduced detailed models for modeling the bar fractures in RC frames under progressive collapse.

In most of the experimental and true-scale studies, little attention has been paid to the effects of transverse beams, and in particular, the additional resistance due to transverse members is not discussed. Hence, a 3D beam-column subassemblage is assessed experimentally in the present study. Investigating the roles of transverse beams in providing alternative load paths under the column removal scenario was the main purpose of the performed evaluation. In addition to the experiment, a finite macro element model is also developed using the open source platform, OPENSEES (2007), to provide comprehensive insight into the experimental observations.

\section{Test Program}

To investigate the role of transverse beams, a 3D subassemblage including three columns, three beams and a middle column stub is tested in the present study. Due to the probable complexities, a 3/10-scaled specimen is used here. The 3D specimen is an extension of a planar (2D) subassemblage that was tested separately by Ahmadi et al. (2016) and the results will be used to provide a better understanding of the effects of the transverse beam. The 2D specimen includes two end columns, a middle column stub and two beams. To make a 3D specimen, a transverse frame consisting of a beam and an end column is added at the middle joint. The specimens were fastened to a displacement control point loaded above the column; the test continued until complete failure of the specimen. During testing, corresponding displacements and strains at predefined points and sections were measured and the formation of resistance mechanisms and failure modes were recorded.

\subsection{Specimen Design}

The specimens tested in the present study are scaled specimens of the full-scale sub-assemblage tested by Lew et al. (2011). The full-scale assembly was selected from a 10-story office building, the design of which was based on an intermediate moment frame (IMF) system. Figure 1 shows the plan of the prototype building along with $2 \mathrm{D}$ and 3D specimens. The building was analyzed base on loads defined in ASCE7-02 (2002) and designed based on ACI codes and commentary ACI 318R-02 (2002). The gravity and seismic load were defined based on information mentioned in Lew et al. (2011) and listed below:

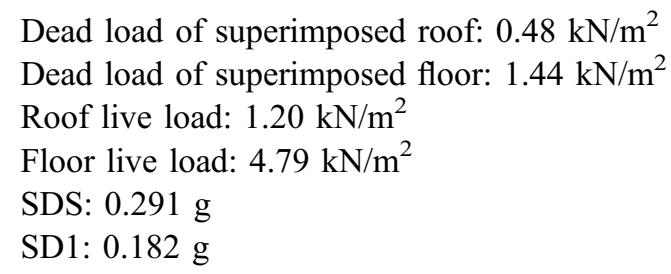

The selected sub-assemblages are parts of an exterior frame of axis 1 between axes B and D on the third floor, as seen in Fig. 1. The first specimen was a 3/10-scale prototype model that was reported by Lew et al. (2011) as an IMF specimen (2D specimen). The specimen presented here is a 3D extension of that first specimen (Fig. 1). Detailed characteristics of the scaled specimens are illustrated in Fig. 2.

As shown in Fig. 2, the upper and lower longitudinal beam reinforcements are anchored mechanically into exterior columns to simulate continuity in external beam-column joints. Given the short length of the specimens, there was no 
(a)

a) ${ }^{200+21500} 200+$
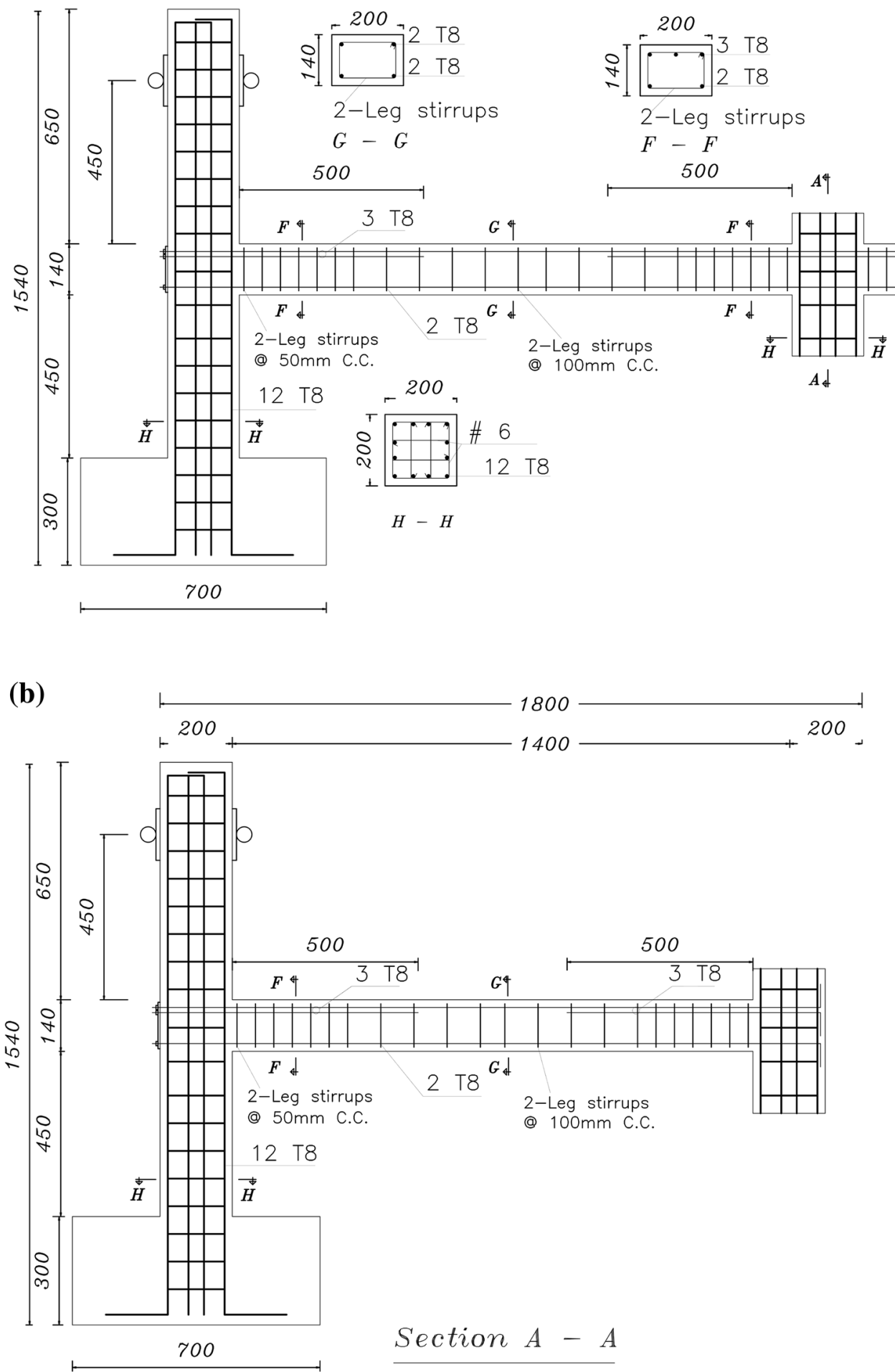

Fig. 2 Details of the test specimens (dimensions in $\mathrm{mm}$ ). a In-plane frame (because of symmetry, a half span of the frame is shown). b Transverse frame.

need to use splices in the beam reinforcements. Longitudinal column reinforcements are anchored by $90^{\circ}$ hooks inside the foundations. To prevent structural slippage, each foundation is attached to the strong laboratory floor using four threaded rods. The tops of the columns were mechanically anchored to the main frame to restrict displacements at these points.
Downward displacement and rotation of the tops of the columns remained unrestrained.

Table 1 lists the characteristics of the prototype and scaled specimens. The difference in reinforcement percentage was caused by access restrictions to bars with characteristics similar to the prototype. 


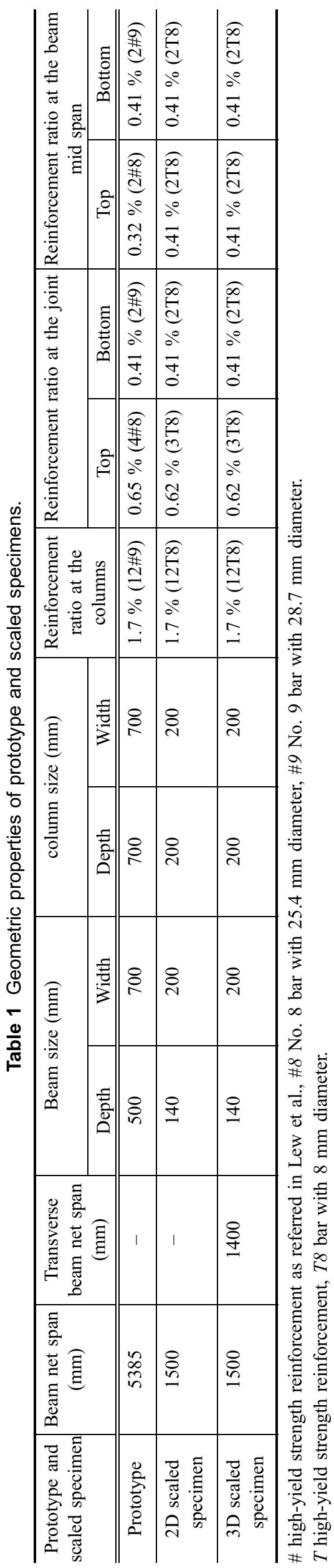

With regard to the scaling of the specimens, the maximum size of the aggregate for the concrete mix design was less than $10 \mathrm{~mm}$. In the technical literature, it is assumed that the ratio of the maximum prototype to the model concrete aggregate is equal to the scale factor of the specimen. Nonetheless, the use of an aggregate with the maximum possible size is always recommended, such that the high relative tensile strength of the model concrete is minimized (Harris and Sabins 1999).

The average compressive and tensile strengths of the concrete were 26 and $1.5 \mathrm{MPa}$, respectively. The yield and ultimate strengths of the beam and longitudinal column reinforcements were 530 and $650 \mathrm{MPa}$, respectively. The rupture strain of the reinforcement was 0.19 , according to the reinforcement tensile tests.

\subsection{Instrumentation}

Layouts of the linear variable differential transformers (LVDTs) are illustrated in Fig. 3. Vertical and horizontal displacements at critical points in the specimen were measured during loading.

Arrangements of the strain gauges on the steel bars are shown in Fig. 4. Thirty-four strain gauges were deployed at predefined locations to record the internal forces of the steel bars as well as different resistance mechanisms within the beams during the tests. The applied vertical force from a hydraulic jack was measured using a load cell.

\subsection{Test Setup and Loading}

Figures $5 \mathrm{a}$ and $5 \mathrm{~b}$ show the setup of the specimens. The experimental details for the $2 \mathrm{D}$ and 3D specimens are similar. To prevent the horizontal movement of the columns, two steel rollers were used to connect the tops of the columns to the main frame. Vertical movements of the columns were not restricted. Vertical load was applied at the middle joint using a hydraulic jack. A 10-mm-thick steel plate was used at the top of the middle column to transfer uniform loads to the middle column stub. A displacement control loading was applied using the hydraulic jack. Four steel channels (UPN 80) were attached to the main beam frame and the floor of the laboratory to prevent out-of-plane displacement. Vertical downward displacement of the middle column was applied in small increments of 5-10 mm. After each increment, the specimen and the instrumentations were checked, cracks were marked and photographs were taken.

\section{Test Results}

The present study focuses on the effects of transverse beams; therefore, the results of the $3 \mathrm{D}$ specimen are discussed in detail and only the differences with the planar subassemblage are highlighted. The specimens were exposed to monotonic downward vertical displacement at the middle column stub until fractures occurred in the lower and upper bars of the beam. Maximum displacement of the middle column at the end of the test was $340 \mathrm{~mm}$ and the chord 
(a)

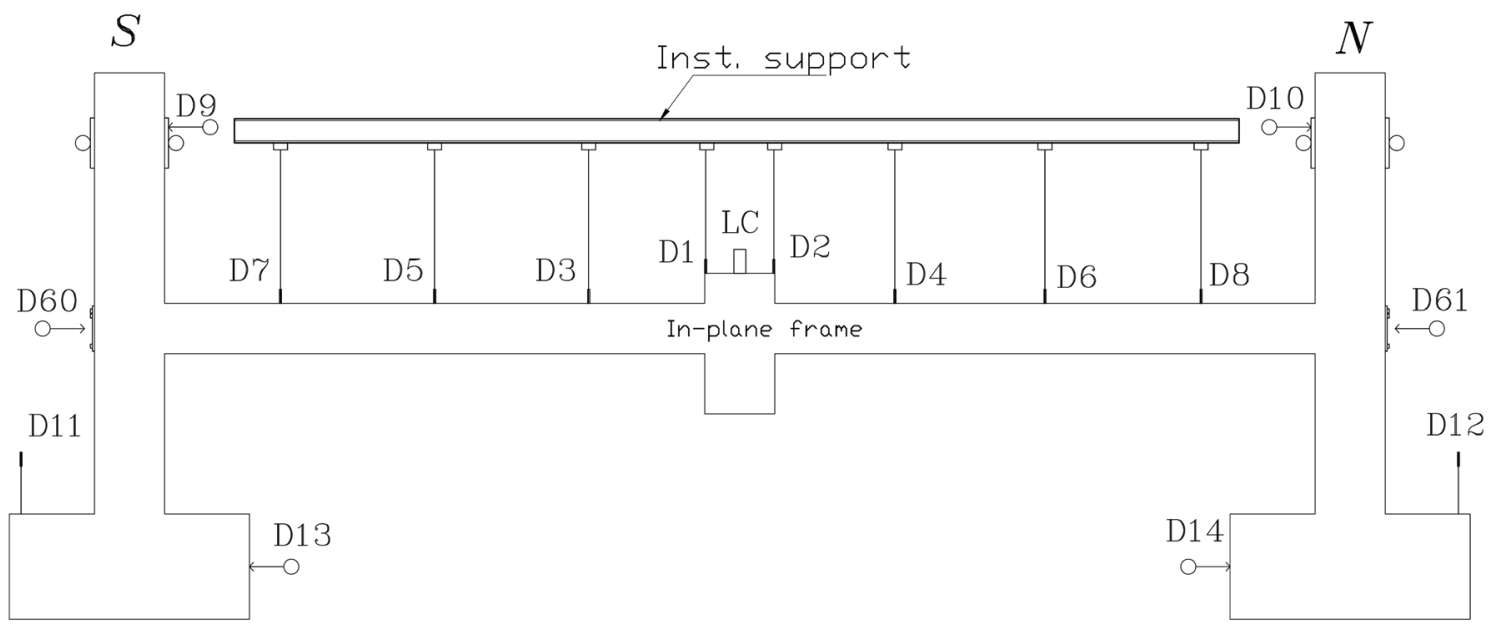

(b)

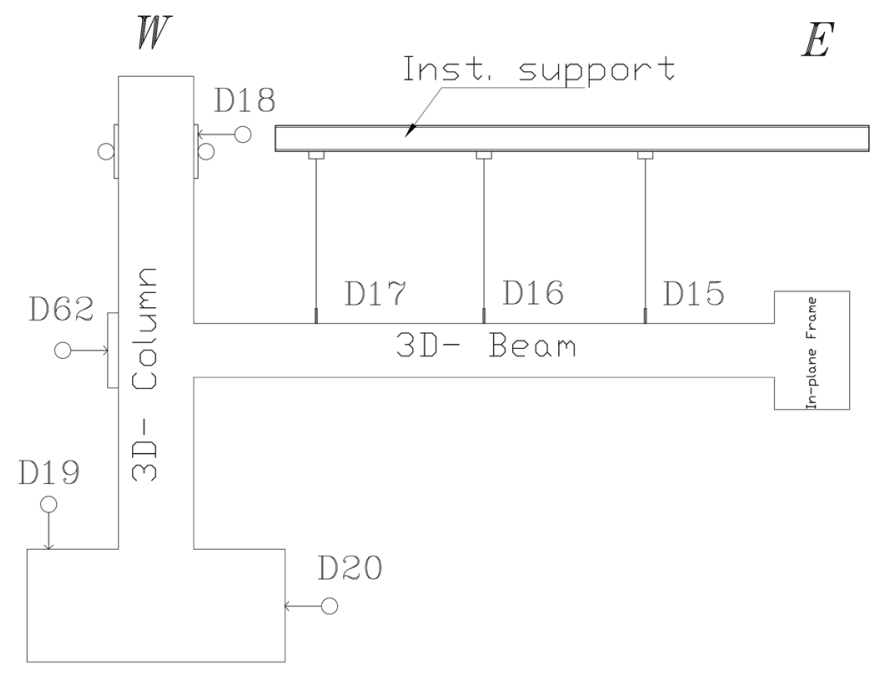

Fig. 3 Layout of displacement measurements. a In-plane frame. b Transverse frame.

rotation of the beam was 0.2 radians $\left(11.46^{\circ}\right)$. The failure of the specimen had the following characteristics: (1) flexural cracks developed at the joints interfaces; (2) the compressive concrete was crushed at the joint interfaces due to the extension of cracks within the upper part of the beams; and (3) fractures occurred in both the beam bottom bars next to the middle column stub and the beam top bars in the exterior beam column joints, in transverse and in-plane beams, respectively.

Failure of the specimen was almost symmetrical until fractures occurred in the beam bottom bars. The failure then developed an asymmetrical configuration because of wide flexural cracks at fracture locations in the rebar. During the test, some inclined cracks developed in the joint panel, but no significant damage occurred. Figure 6 shows the fracture of bars in the 3D specimen.

\subsection{Crack Patterns}

Applying vertical downward displacement on the middle column led to the gradual formation of flexural cracks in the beams next to the joints interfaces. At a vertical displacement of $25 \mathrm{~mm}$, corresponding to a vertical load of $29 \mathrm{kN}$, the flexural cracks widened and inclined cracks developed at the joint panel of the external beam-column connections. For a vertical displacement of $150 \mathrm{~mm}$ and vertical load of about $34 \mathrm{kN}$, the width of the main flexural cracks was measured at about $8 \mathrm{~mm}$. By reaching a vertical displacement of $170 \mathrm{~mm}$, concrete crushing in the areas of the beams subjected to high compression near the middle column and the bottom of the beams at both beam ends were observable. The development of tensile forces within the beams led to the extension of deep cracks at the reinforced cut-off sections. The cracks in the joint interfaces at the end of this stage are illustrated in Fig. 7.

One of the lower bars of the south beam next to the middle joint fractured at a displacement of $276 \mathrm{~mm}$, corresponding to a load of $53 \mathrm{kN}$. A second rupture occurred at the same place with a displacement of $300 \mathrm{~mm}$ and a vertical load of $51 \mathrm{kN}$. Fractures in the lower bars led to a crack opening in this location. Fractures in the upper bars accrued at the external joint in the transverse beam. Consequently, the upper bars in the south beam started to fracture with a displacement and load of $340 \mathrm{~mm}$ and $53 \mathrm{kN}$, respectively. The test was terminated following the development of this 
(a)

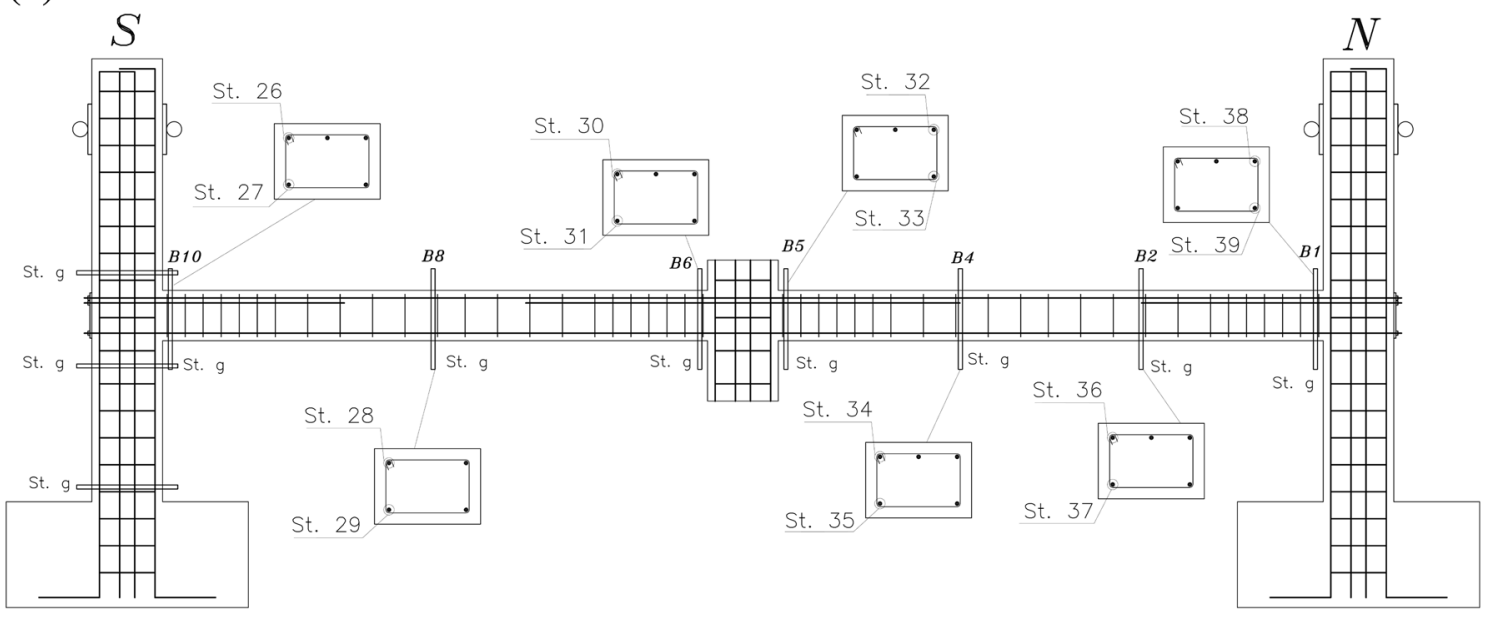

(b)

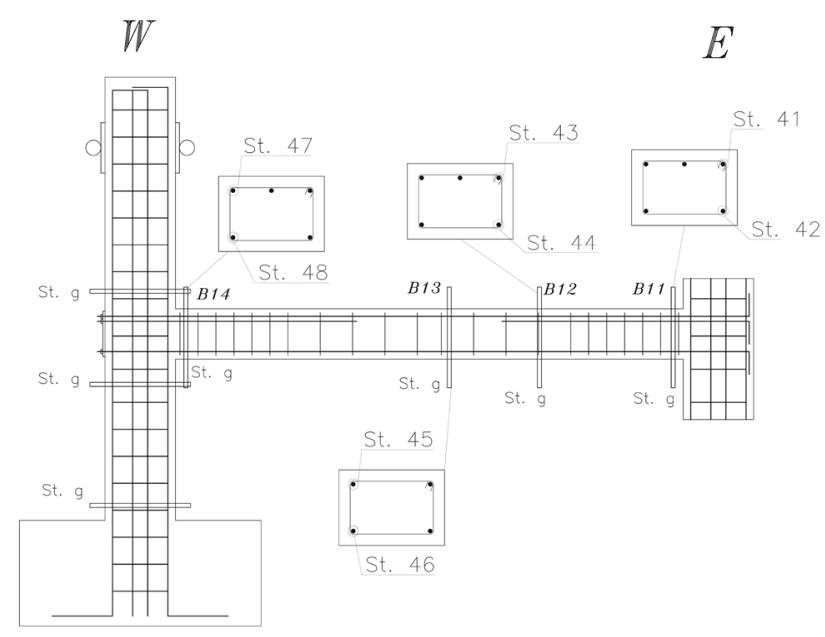

Fig. 4 Layout of reinforcement strain gauges. a In-plane frame. b Transverse frame.

fracture due to the considerable drop in the load-carrying capacity. Figure 8 illustrates the crack patterns in the end columns at the end of the test.

Figure 9 compares the crack patterns of 2D and 3D specimens. The crack patterns and overall behavior of the 3D specimen demonstrate a more symmetrical and ductile behavior during early stages of loading. Specimens with a transverse beam deflected symmetry are observed to have the same crack pattern in the south and north beams. In addition, the ductility and strength of the specimen were significantly increased because of the transverse beam capacity. On the other hand, the rotation of the middle joint was not restricted in the 2D frame. Flexural cracks were concentrated at the south interface of the beam and the column stub that caused fractures in the lower bars of the beam. Crack openings and bar fractures led to a sudden drop in the load carrying capacity of the $2 \mathrm{D}$ specimen.

Comparison of final crack pattern (Fig. 10) shows that despite the general similarity, the number of cracks in the $2 \mathrm{D}$ specimen was considerably lower. Additionally, cracks in the 3D specimen were deeper, especially in the mid-span of the beams, which can be an indication of more axial tension in the beam during the final stages of loading.

\subsection{Load-Displacement Curve}

The vertical load versus vertical deflection of a middle column is depicted in Fig. 11. In order to compare the general behavior of $2 \mathrm{D}$ and $3 \mathrm{D}$ specimens, the load-displacement curve of the $2 \mathrm{D}$ specimen is also shown. At a vertical displacement of $67 \mathrm{~mm}$, which is equal to half of the beam depth, the load reached an initial peak of $38.2 \mathrm{kN}$. This point corresponds to the compressive arch action (CAA) capacity of the beams. With additional increments in the vertical displacement, the vertical load started to decrease, and continued to do so until a vertical displacement of $151 \mathrm{~mm}$, which is approximately equal to the beam depth. Beyond this point, the development of tensile force in the beams led to increased vertical load capacity. This point is considered as the initiation of increasing the capacity due to catenary action (CA) mechanism of the in-plane frame.

Increasing displacement up to $276 \mathrm{~mm}$ increased the vertical load, resulting in the first fracture in the lower longitudinal bar in the beam with a vertical load of $53 \mathrm{kN}$. The first rebar fracture occurred at the location of the main crack in the south beam at the interface with the middle column stub. The second fracture in the beam's lower rebar occurred at the same place with a displacement and load of $297 \mathrm{~mm}$ and $51 \mathrm{kN}$, respectively. 
(a)

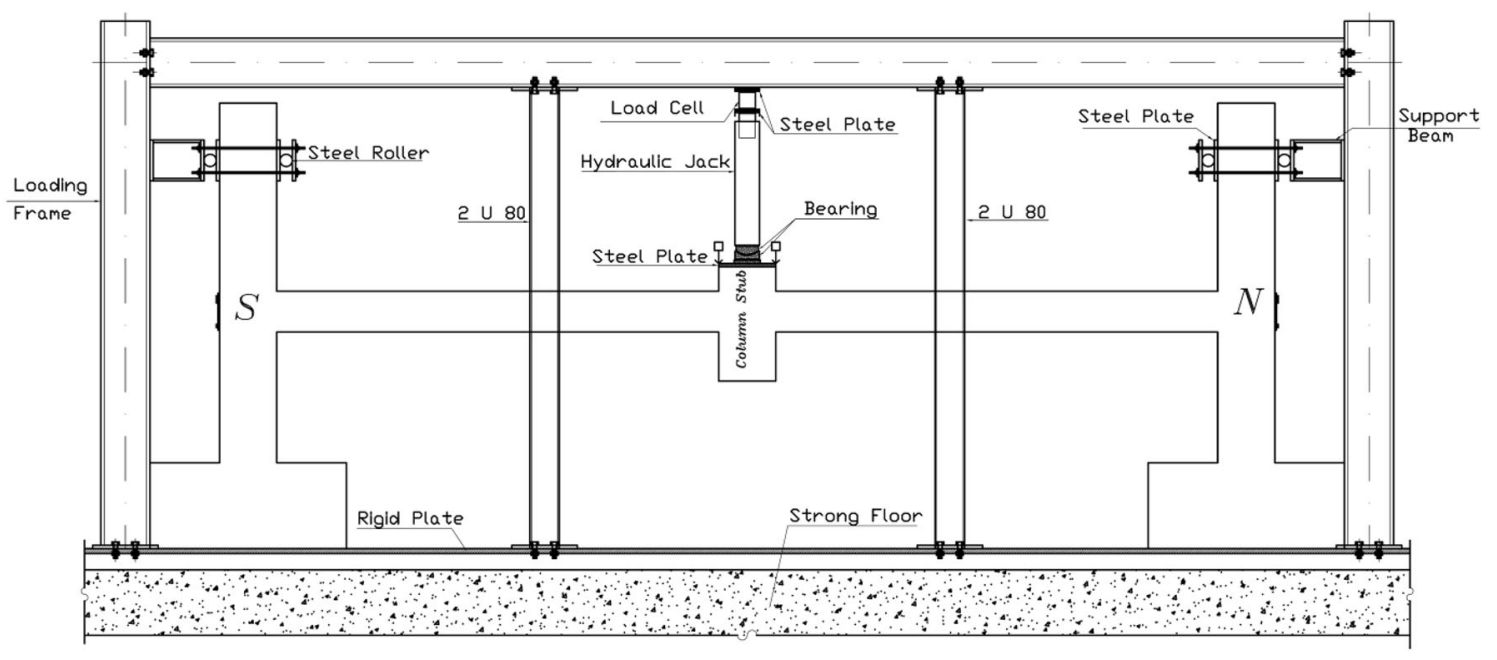

(b)

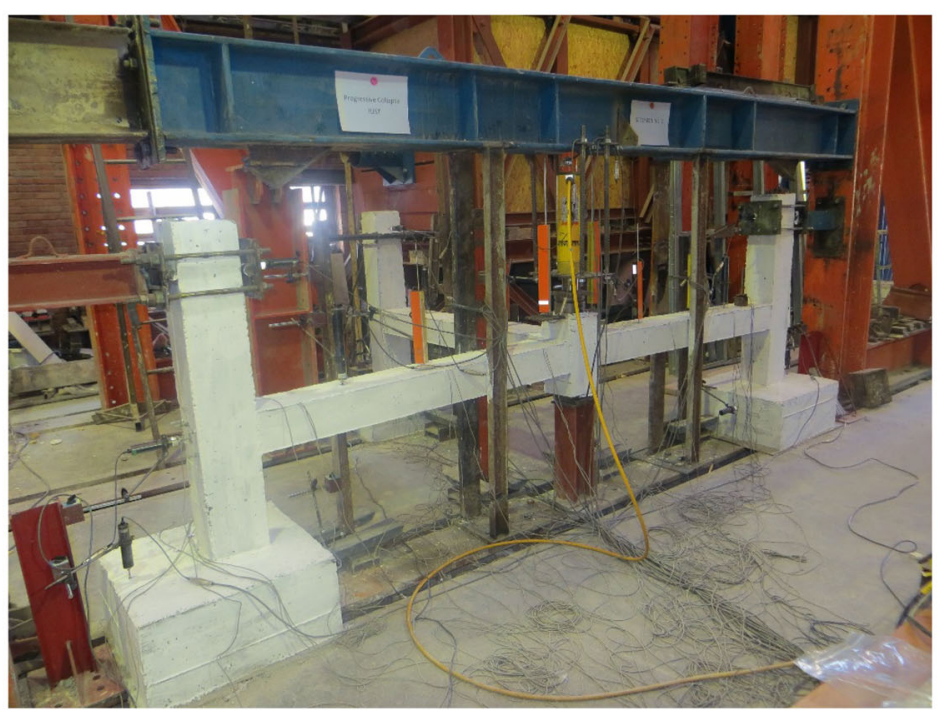

Fig. 5 Setup of the test specimens. a Test setup (in-plane frame). b Test setup (3D view).

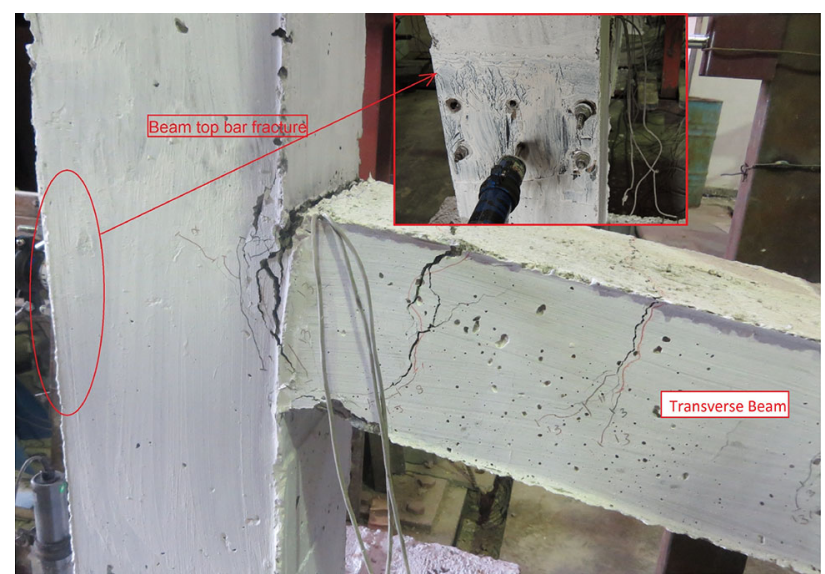

Fig. 6 Fracture of top bars at the end of the test.

Finally, by increasing the displacement up to $340 \mathrm{~mm}$, the upper bars at the external connection of the transverse beam were fractured. Consequently, one of the top bars at the end connection of the south beam was fractured and testing had to terminate due to a drastic drop in the load carrying capacity of the sub-assemblage. In Fig. 11, the points on the longitudinal bar fractures are shown. Figure 12 shows images of the lower rebar fractures at the middle joint interface.

Loads and displacements at significant points are listed in Table 2. Classifications of the different stages according to the resistance mechanisms are also represented (Table 2). The lower and upper reinforcement at the middle and end joint interfaces of the main (in-plane) frame yielded quickly during the initial loading steps. Yielding of the beam reinforcement created plastic hinges in the beams, which shows that flexural action had reached its capacity. Because of the $3 \mathrm{D}$ geometry of the specimen, the transverse beam is expected to gain plastic capacity with higher vertical displacements. Figure 13 demonstrates the strain in three tensile steel bars at the joint interfaces where the main flexural cracks are developed (sections B1, B6 and B14 in Fig. 4). According to this figure, tensile steel bars at the main frame joint interfaces yielded quickly during the initial stages of 

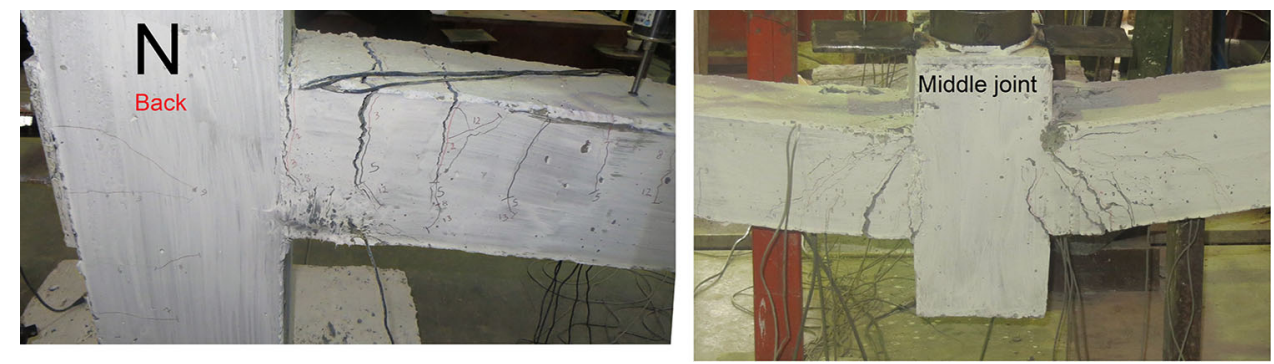

Fig. 7 Crack pattern for a displacement of $170 \mathrm{~mm}$.
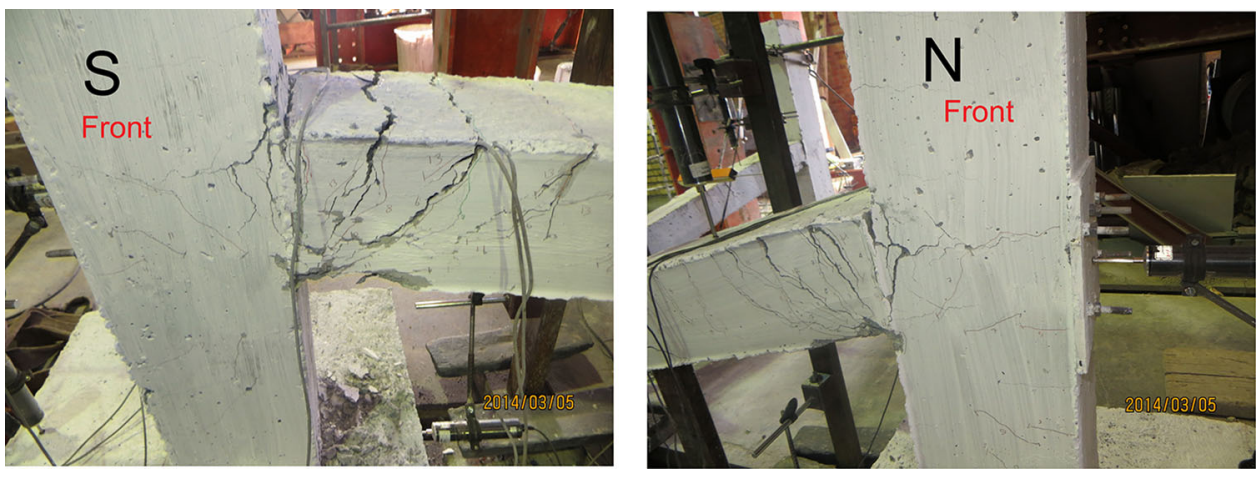

Fig. 8 Crack pattern at the end of the test.
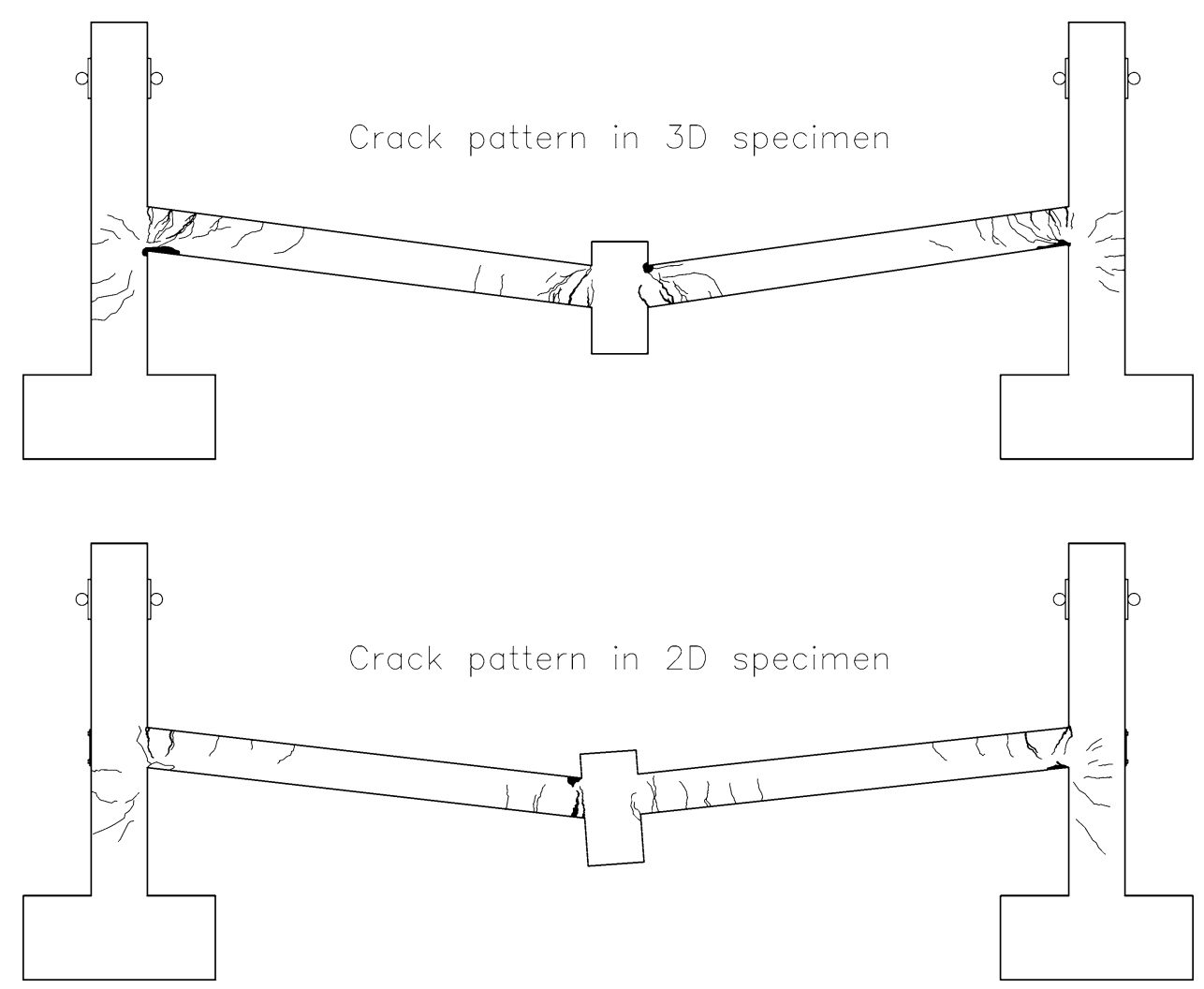

Fig. 9 Comparison of crack patterns in 2D and 3D specimens for vertical displacements of $170 \mathrm{~mm}$.

the test. The displacement and load corresponding to reinforcement yielding in the main frame were $16.9 \mathrm{~mm}$ and 23 $\mathrm{kN}$, respectively. Tensile bars in the transverse beam yielded a displacement of about $30 \mathrm{~mm}$, which is equal to a vertical load of $32 \mathrm{kN}$. Considering this point to be a plastic hinge mechanism of the sub-assemblage, the transverse beam enhanced the flexural capacity of a 3D specimen by up to 55 percent (Table 2).

The first peak in the load-displacement curve corresponds to the CAA capacity of the sub-assemblage. In comparison 

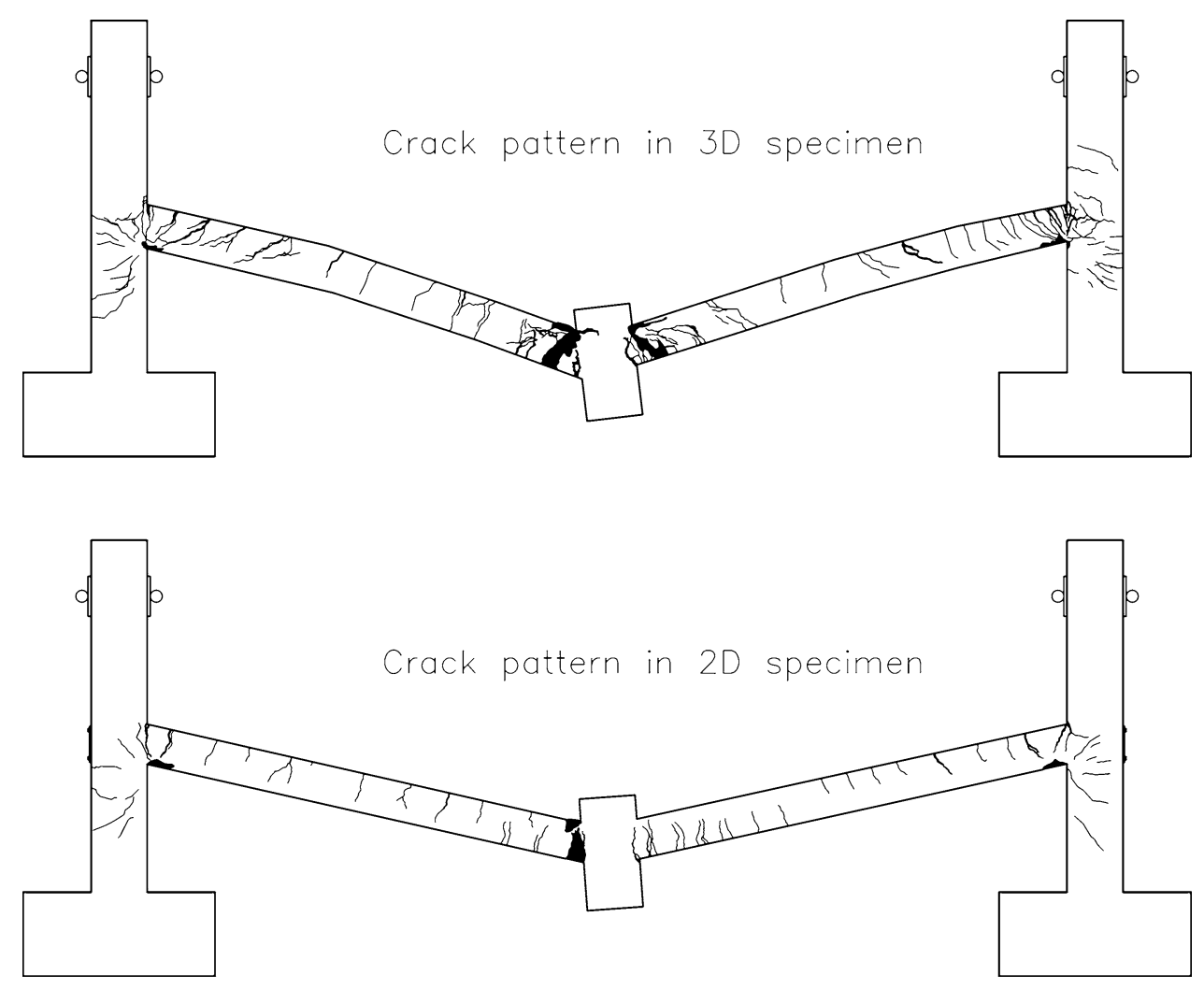

Fig. 10 Comparison of crack pattern in $2 D$ and $3 D$ specimens at the end of tests.

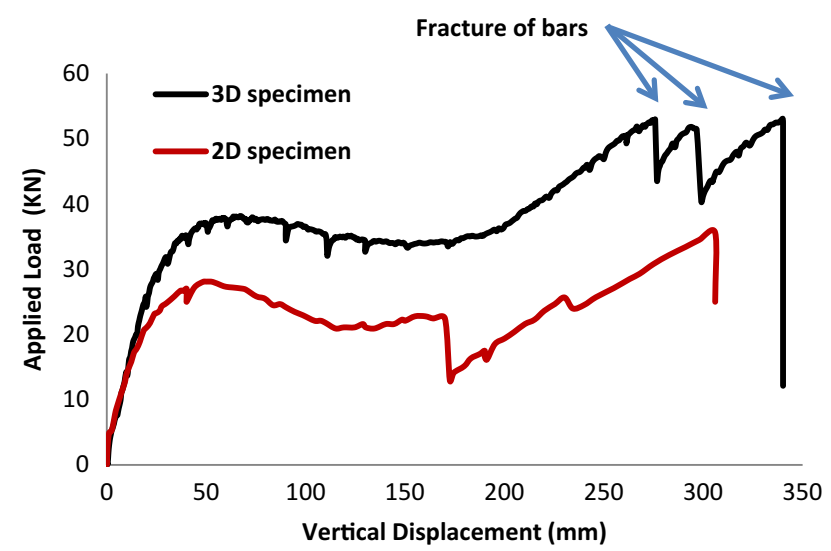

Fig. 11 Vertical load versus vertical deflections of specimens at the center column.

to the flexural capacity, arching action enhances the structural resistance by up to 19 percent. Comparison of $2 \mathrm{D}$ and $3 \mathrm{D}$ results demonstrated that $\mathrm{CAA}$ for a $2 \mathrm{D}$ frame enhances the structural resistance by about 36 percent over flexural

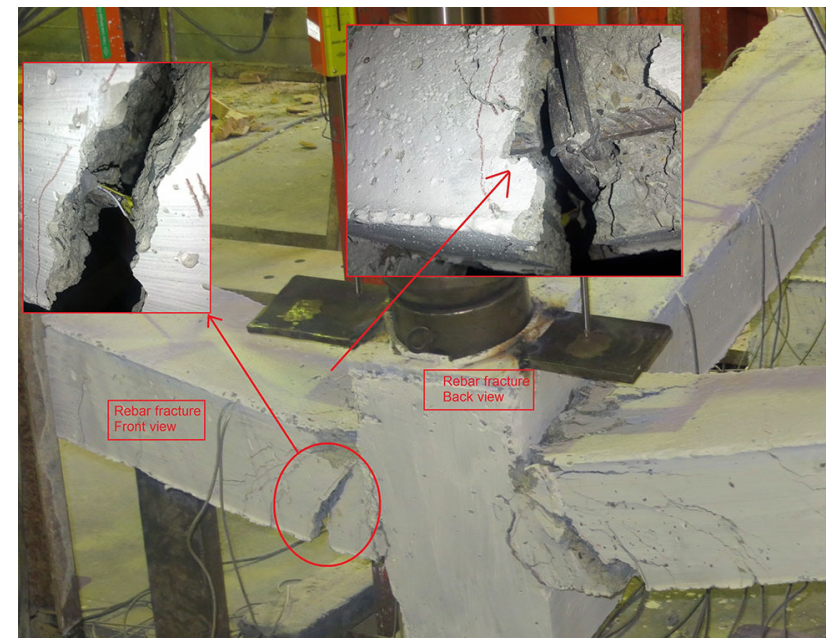

Fig. 12 Fracture of bars at the middle joint interface.

capacity but in a 3D frame this increase is 19 percent. As mentioned above, the development of compressive forces enhances CAA capacity and the transverse beam in the 3D

Table 2 Comparison of Force and displacement at critical points of $2 \mathrm{D}$ and 3D specimen.

\begin{tabular}{c|c|c|c|c|c|c|c|c}
\hline \multirow{2}{*}{ Specimen } & \multicolumn{2}{|c|}{ Flexural action } & \multicolumn{2}{c|}{ Compressive arch action } & \multicolumn{2}{c|}{ beginning of catenary action } & \multicolumn{2}{c}{ Catenary action } \\
\cline { 2 - 9 } & $\mathrm{P}(\mathrm{FA})(\mathrm{kN})$ & $\mathrm{Y}(\mathrm{FA})(\mathrm{mm})$ & $\mathrm{P}(\mathrm{CCA})(\mathrm{kN})$ & $\mathrm{Y}(\mathrm{CCA})(\mathrm{mm})$ & $\mathrm{P} 0(\mathrm{CA})(\mathrm{kN})$ & $\mathrm{Y}(\mathrm{CA})(\mathrm{mm})$ & $\mathrm{P}(\mathrm{CA})(\mathrm{kN})$ & $\mathrm{Y}(\mathrm{CA})(\mathrm{mm})$ \\
\hline \hline 2D specimen & 20.7 & 18.5 & 28.1 & 50 & 21 & 135 & 35.6 & 306 \\
\hline 3D specimen & $23-(32)$ & $16.9-(30)$ & 38.18 & 67 & 33.2 & 151.2 & 53 & 340 \\
\hline Difference \% & $11.1-(55)$ & $9.5-(62)$ & 36 & 35 & 58 & 12 & 49 & 11 \\
\hline
\end{tabular}

Numbers in parenthesis are for stage of plastic hinge development in transverse beam. 


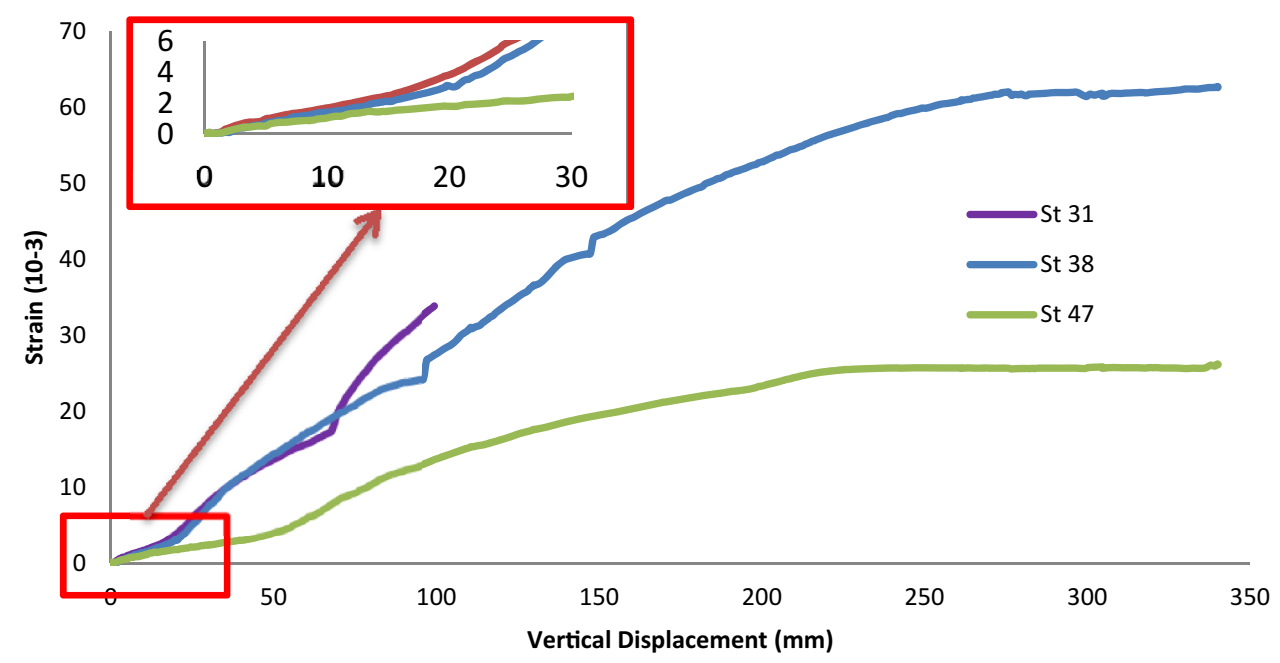

Fig. 13 Strains of reinforcing bar at beam ends versus vertical displacement.

Table 3 Force and displacement at critical points of load-deflection curves.

\begin{tabular}{|c|c|c|c|c|c|c|c|c|c|}
\hline & \multicolumn{2}{|c|}{ Flexural action } & \multirow{2}{*}{\begin{tabular}{|c|} 
CAA action \\
Experimental
\end{tabular}} & \multirow{2}{*}{$\begin{array}{c}\text { Second part } \\
\text { of load } \\
\text { increasing } \\
\end{array}$} & \multirow{2}{*}{$\begin{array}{l}\text { 1st rebar } \\
\text { fracture }\end{array}$} & \multirow{2}{*}{$\begin{array}{l}\text { 2st rebar } \\
\text { fracture }\end{array}$} & \multirow{2}{*}{$\begin{array}{l}\text { Top rebar } \\
\text { fracture }\end{array}$} & \multicolumn{2}{|c|}{ Catenary action } \\
\hline & Calculated & Experimental & & & & & & Calculated & experimental \\
\hline $\begin{array}{c}\text { Displacement } \\
(\mathrm{mm})\end{array}$ & - & 16.9 & 67 & 151 & 276 & 297 & 340 & 320 & 340 \\
\hline Force $(\mathrm{KN})$ & $19.4(25.7)^{*}$ & 23 & 38 & 33 & 53 & 51 & 53 & 59.9 & 53 \\
\hline
\end{tabular}

* With assumption of plastic hinge development in main and transvers beams.

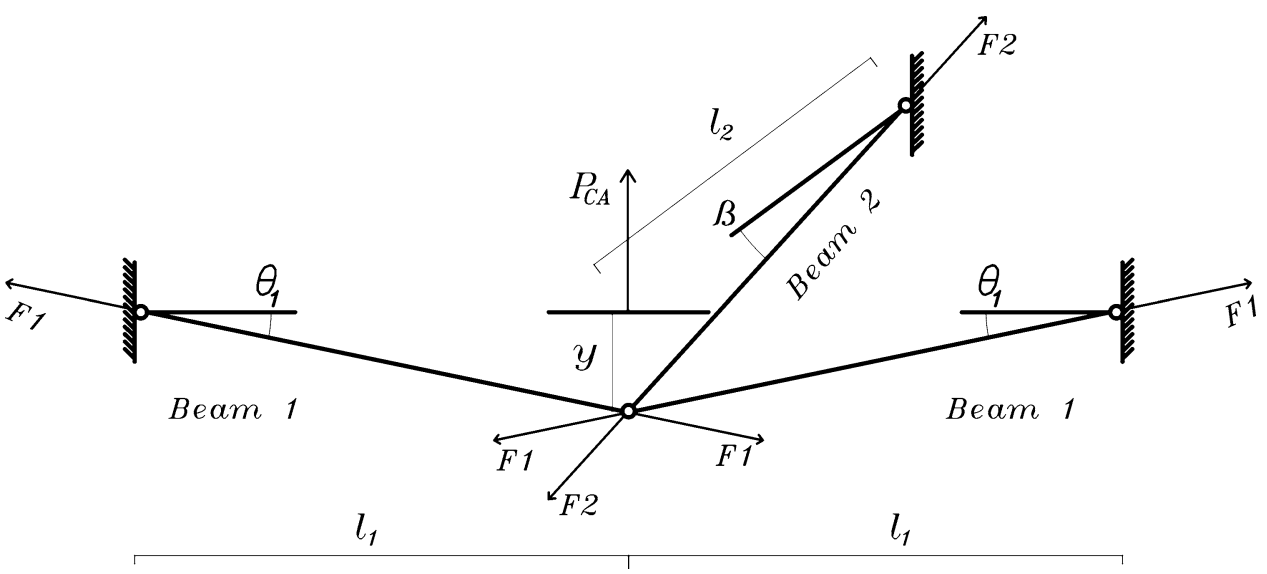

Fig. 14 Force equilibrium diagram for the CA stage.

specimen does not have enough restriction at its ends for the development of an axial force and arching action. Indeed, the CAA capacity for both specimens had the same resistance elements and mechanisms.

Large deflections and crack development at the depth of the beams led to the gradual elimination of compressive axial forces and the consequent reduction in the load carrying capacity of the specimen. The load capacity of the specimen up to a displacement of $151 \mathrm{~mm}$ and loading force of $33 \mathrm{kN}$ decreased. Beyond this point, the vertical load increased because of the development of tensile forces in the beams.
Table 3 shows the forces and displacements at critical points in the load-displacement curve. The nominal flexural capacity of the sub-assemblage was calculated based on conventional plastic mechanisms (Table 3). The experimental flexural capacity was greater than the calculated nominal flexural capacity. This is because of the development of compressive force in the beams, even at initial stages of loading.

In Table 3, the capacity of catenary action has been calculated based on simple analysis proposed by Jian and Zheng (2014), with some modifications. The free body diagram of the assemblage is presented in Fig. 14. 
Horizontal and vertical equilibrium equations for the beam axial force resulted in:

$$
P_{C A}=\frac{2 \cdot T_{u 1} \cdot y_{C A}}{l_{1}}+\frac{T_{u 2} \cdot y_{C A}}{l_{2}}
$$

where $T_{u}$ is the tensile resistance of the beams, $y_{C A}$ is the middle joint vertical deflection that corresponds to $\mathrm{CA}$ capacity, and $l_{1}$ and $l_{2}$ are the effective spans of the main and transverse beams, respectively.

In the technical literature, $y_{C A}$ is adopted as $10 \%$ of the total two-bay beam span length of the main frame, which has been confirmed by several experiments. Hence, Eq. (1) can expressed as:

$$
P_{C A}=0.4 T_{u 1}+0.2 T_{u 2} \frac{l_{1}}{l_{2}}
$$

An examination of several structural 2D progressive collapse experiments shows that tensile resistance could be computed by considering only the upper reinforcing steel at the middle joint. The upper reinforcement of the transverse beam of the specimen in this study fractured during the final stage of loading. Consequently, the upper rebar of the main beam at the south end fractured and the load carrying capacity decreased. Hence, it is rational to consider the CA capacity while considering the top bars as only being resisting elements. Thus, Eq. (2) can be rewritten as:

$$
P_{C A}=0.4 A_{s 1-t o p} f_{u 1-t o p}+0.2 A_{s 2-t o p} f_{u 2-t o p} \frac{l_{1}}{l_{2}}
$$

As presented in Table 3, there was little difference between the calculated values and the results obtained from the CA capacity tests for a 3D specimen. Fracture of the upper beam bars occurred at a value between yield and ultimate strength in response to the stress concentration at the middle and end joint interfaces and the effect of shear force on rebar under tension.

The load-displacement curves were identical for the 2D and 3D specimens up to a vertical displacement of $18 \mathrm{~mm}$. Because the flexural and arching actions of the in-plane beams are dominant during this stage, this similarity is

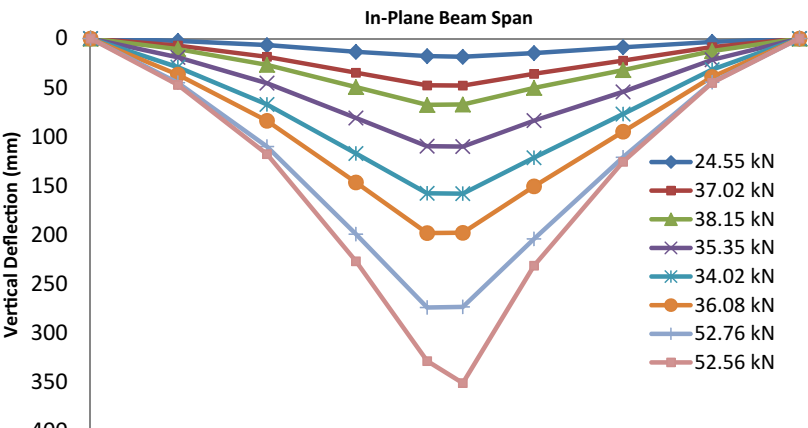

Fig. 15 Deflection profiles of specimen corresponding to indicated load steps.

obvious. Numerical analyses in the next section demonstrate that within this stage, small axial forces were developed in the transverse beam. Generally, owing to the lack of axial restraint in the transverse beam, arching actions could not develop. Hence, flexural action is the dominant mechanism in the transverse frame. The flexural capacity of a transverse frame leads to higher resistance for 3D specimen events - in the post peak phase of the load-displacement curve (Fig. 11). The area under the load-displacement curve for the $3 \mathrm{D}$ specimen is 1.9 times larger than the corresponding value for the $2 \mathrm{D}$ assembly.

\subsection{Deflection Profile}

The beam deflection profile of the $3 \mathrm{D}$ specimen during the different steps of the test is estimated with line between pairs of measurement points (Fig. 15). Note that an almost symmetrical profile is achieved for the $3 \mathrm{D}$ specimen up to the fracture of the lower bars, which occurred with a vertical displacement of $276 \mathrm{~mm}$. Beyond this point, the profile has an asymmetric configuration.

\subsection{Strain Measurements}

To analyze the internal forces in the beams and columns, 34 electrical resistance strain gauges were attached to the embedded reinforcing bars. The locations of the strain gauges are presented in Fig. 4. As presented in the previous
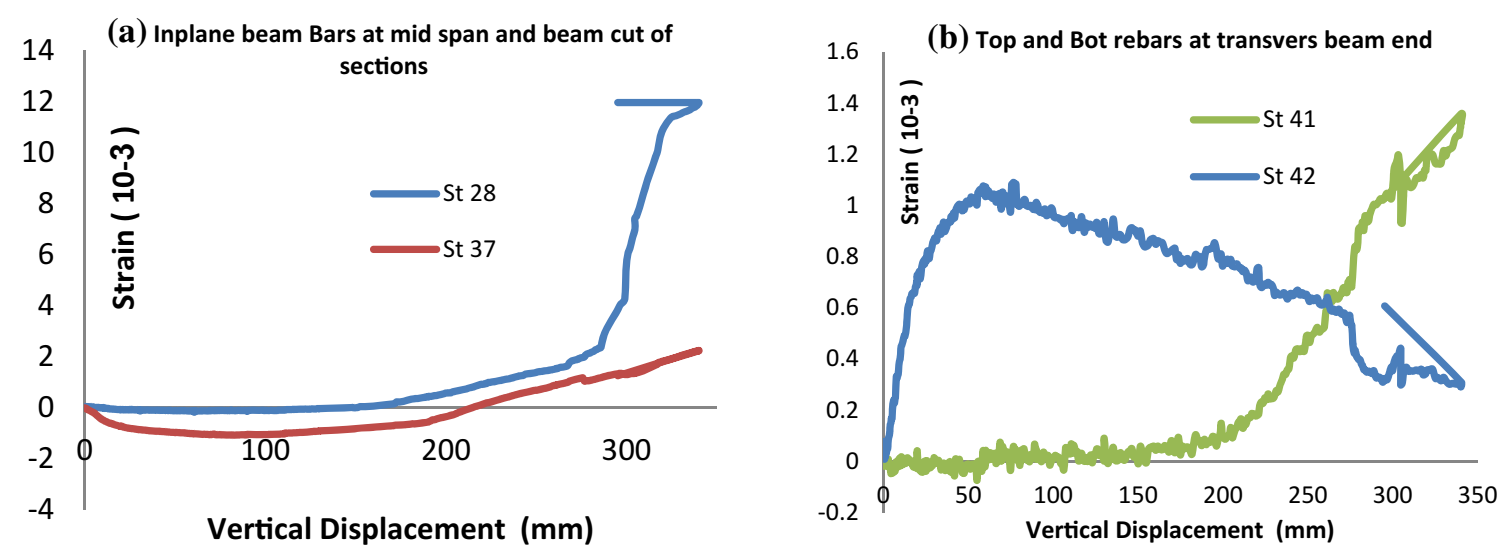

Fig. 16 Strains of reinforcing bars. 
section, various structural mechanisms can be studied from strain measurements as was done for flexural actions. The strains of the upper bars at the mid-span of northern beam (ST. 28) and the lower bar at the cutoff section in southern beam (ST. 37) (Fig. 16a) show that, at displacements less than $150 \mathrm{~mm}$, the strains in both the upper and lower bars were negative, indicating the development of compressive forces within the beams. At displacements between 150 and $220 \mathrm{~mm}$, the strains in the reinforcement gradually changed from compression to tension. At vertical displacements greater than $220 \mathrm{~mm}$, positive strain developed through all of the longitudinal bars, clearly indicating the development of catenary action within the beams.

The reinforcement strains in the top and bottom rebars at section B11 at the transverse beam (Fig. 16b) show that the strains in the reinforcement in this section remained in the elastic range. In addition, tensile strain in the top and bottom rebars indicates the development of axial tension during the second half of the loading procedure.

The experimental results in the present study demonstrate the significant role of transverse frames in the redistribution of unbalanced loads resulting from a column removal scenario. With RC moment frames, a consideration of the redistribution of unbalanced loads in all directions leads to more economical and precise design.

\section{Numerical Analysis}

Numerical evaluation is performed to provide a more comprehensive insight into the collapse behaviors of the tested sub-assemblages. Large deformations in structural members under column removal scenarios increase the complexity of the analysis using finite element methods. Analyses of geometric and material nonlinearity, which structures experience during progressive collapse, are far beyond the typical conditions considered in the development of finite element platforms or conventional design codes.
Also severe cracking and bar fractures are not easily applicable in finite element simulations. The behavior of beamcolumn joints is neglected in typical software applications using beam and column elements. Non-elastic behavior in conventional analyses was limited to the flexural yielding of beams and columns, whereas experimental and analytical studies revealed the effects of connections in the general behavior of structural systems, especially during earthquakes or the progressive collapse of structures as investigated by Bao et al. (2014), Lew et al. (2014) and Lowes and Altoontash (2003). In the present study, the OPENSEES open-source platform is used to analyze the sub-assemblages affected by column removal scenarios.

\subsection{Modeling Approach}

Beams and columns were modeled using displacementbased beam-column fiber elements that could provide the desired nonlinear characteristics needed for progressive collapse analysis. Non-elastic behaviors of beam column connections were modeled using the 3D joint model introduced by Altoontash (2004). Figure 17 shows the configuration of the joint element idealized as a parallelepipedshaped shear block. This joint model is constructed over six

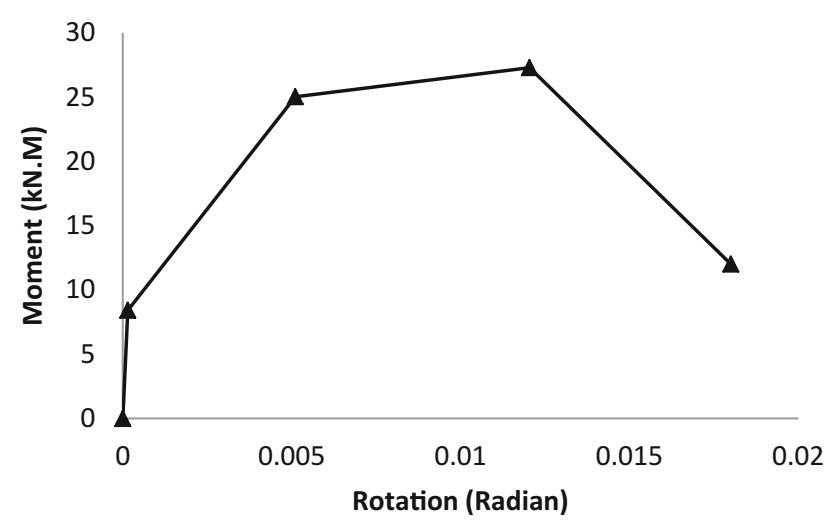

Fig. 18 Moment-rotation relationship for shear panel spring.
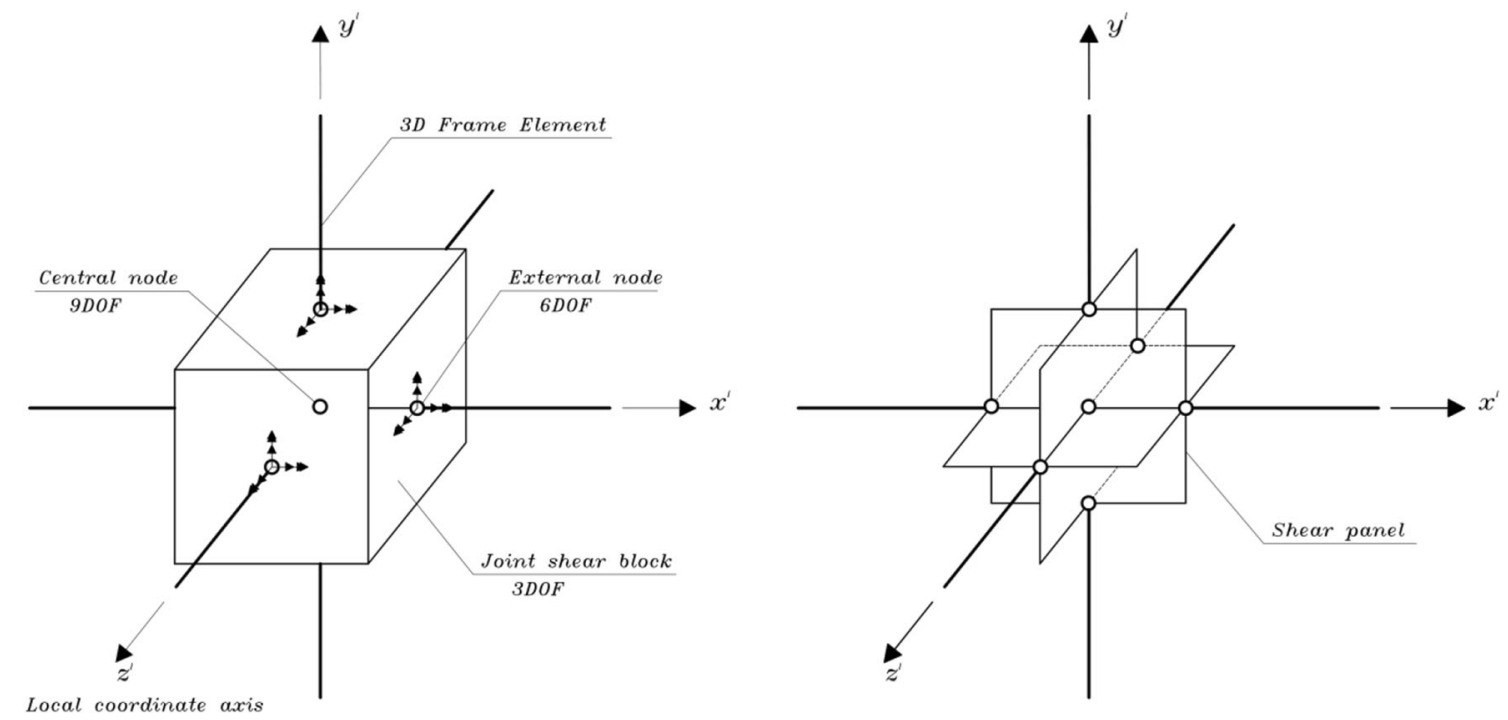

Fig. 17 Configuration of the 3D joint element. 
external nodes with each node located at the center of one of the parallelepiped faces. This model includes three rotational springs at the central node of the block used to model the shear behavior of a joint panel for three principal orthogonal planes. Further details can be found in Altoontash (2004). The membrane2000 software by Bentz (2000) based on modified compression field theory (1986), was used to calculate the properties of the shear panel springs. The momentrotation relation for an in-plane shear panel of the tested specimen is plotted in Fig. 18.

To consider rotations of the joint interfaces due to bond slip and yielding of steel bars, a zero-length section element was used to attach the beams and columns to the joint block. Bar-slip formulation in the configuration of the bilinear steel material is used for zero length section elements to consider bar slip in joint interfaces. The bar fracture is considered by using maximum and minimum strain in reinforcing steel materials. Shear behavior of the beam-joint interface is modeled by zero length elements with the elastic material at the joint interface of beams. A uniaxial constitutive model with linear tension softening (concrete02) was used to model the concrete material. Reinforcement was modeled as reinforcing steel material from the software library by applying maximum and minimum strains for modeling the rebar fracture. The tests performed in the present study, along with the experimental tests in literature, were used to calibrate the numerical model.

\subsection{Calibration of Modeling}

No similar tests for calibrating a numerical model have been presented in the wide range of literature on the experimental study of progressive collapse that has been reviewed. Because of this deficiency, the tests performed in the present study, as well as the 2D full-scale laboratory tests by Lew et al. (2011), have been used to calibrate the numerical models. Two specimens representative of Intermediate Moment Frames (IMF) and Special Moment Frames (SMF) were designed and tested under monotonic downward loading by Lew et al. (2011). The IMF model specimen $\mathrm{N} 1$ is used for a parametric study in Sect. 4.4. The 2D and
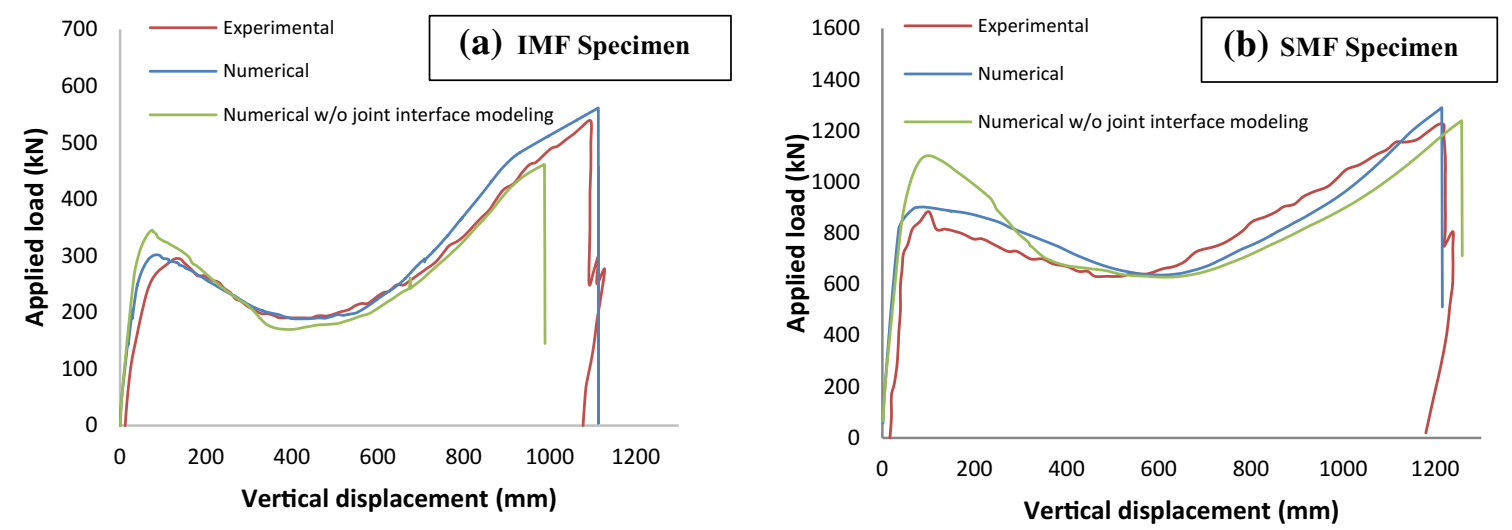

Fig. 19 Numerical and experimental load-deflection results for IMF and SMF specimens.

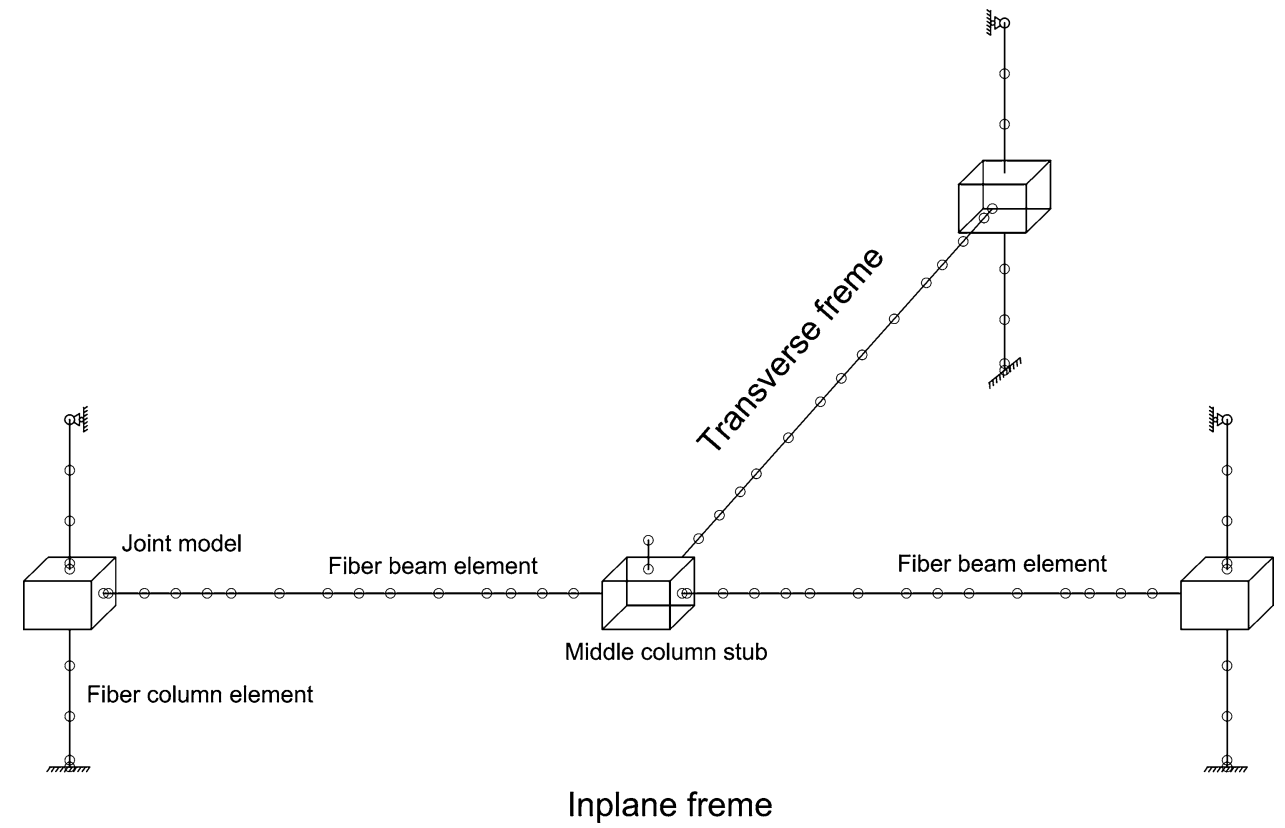

Fig. 20 Numerical model of 3D sub-assemblage. 

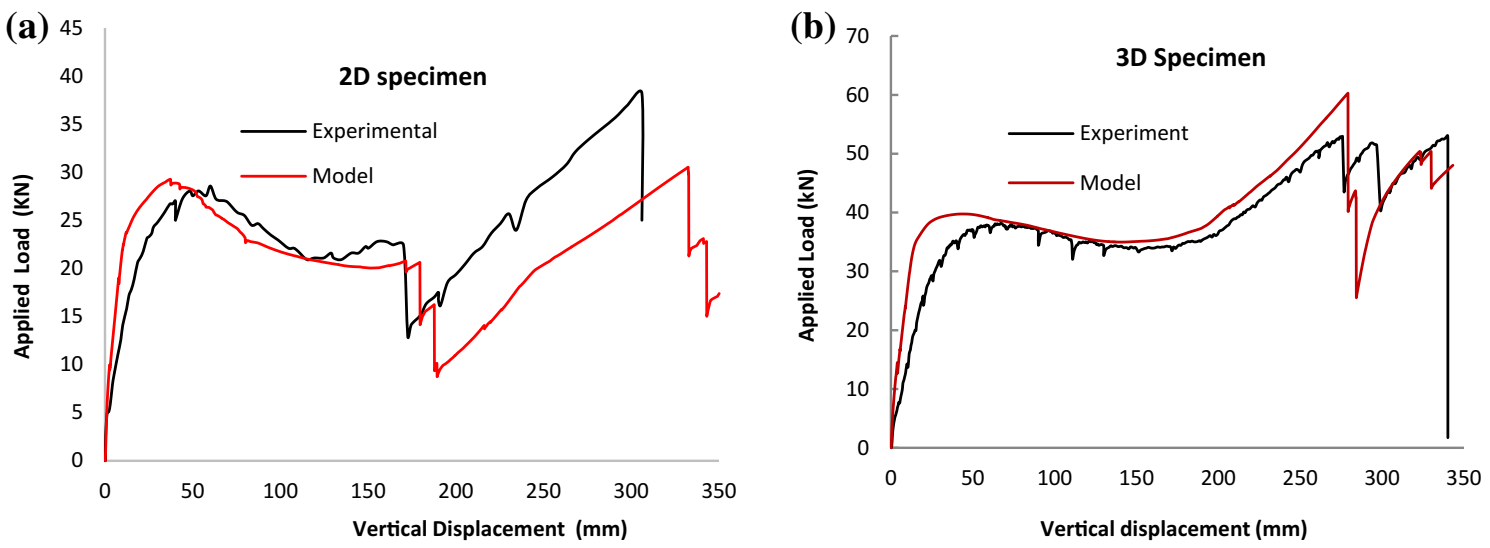

Fig. 21 Numerical and experimental load-deflection results. a 2D specimen, b 3D specimen.

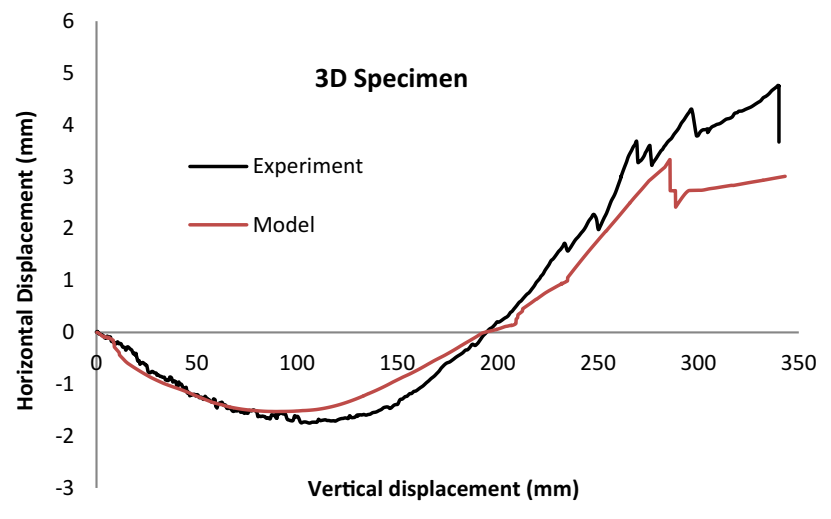

Fig. 22 Horizontal displacement of end columns versus vertical displacement of the center column.

3D specimens are the subject of the experimental work in this study. These specimens were identical in dimensions and detailing, but the 3D specimen had an additional transverse frame. The characteristics of these two specimens were identical and reported in the specimen detail in Sect. 2.

Numerical and experimental load-displacement curves for the IMF and SMF specimens are plotted in Figs. 19a and $19 \mathrm{~b}$, respectively. The results of the numerical model, assuming end offsets and rigid connection behavior, are also presented. There is good agreement between the numerical and experimental results. Ignoring the connection behavior caused an up-to-30\% overestimation of the bearing capacity in the CAA capacity in the numerical model.

The numerical model of the $3 \mathrm{D}$ sub-assemblage that is tested in the present research is illustrated in Fig. 20. The characteristics of the materials used in the numerical model were based on laboratory work. Figures $21 \mathrm{a}$ and $21 \mathrm{~b}$ compare the numerical and experimental load-displacement curves of the 2D and 3D specimens, respectively, and indicates a general agreement between the results.

\subsection{Investigation of Numerical Model Results}

Horizontal displacements of in-plane end columns at the beam mid heights (Fig. 22) show that experimental and numerical results generally have good agreement, especially before bar fractures. In the last third parts of the curves, different failure mechanisms in the experimental and numerical models lead to differences in the results.

Figures 23a and 23b represent the axial forces versus vertical displacement of the middle joint for the main and transverse beams, respectively. According to the numerical results, axial compressive forces are in compression, increasing at the main beam up to a vertical displacement of $50 \mathrm{~mm}$ with a maximum value of $74 \mathrm{kN}$. At greater values of vertical displacement, these compressive forces start to decrease, and at a vertical displacement of $170 \mathrm{~mm}$, change from compression to tension. Beyond this point, tensile
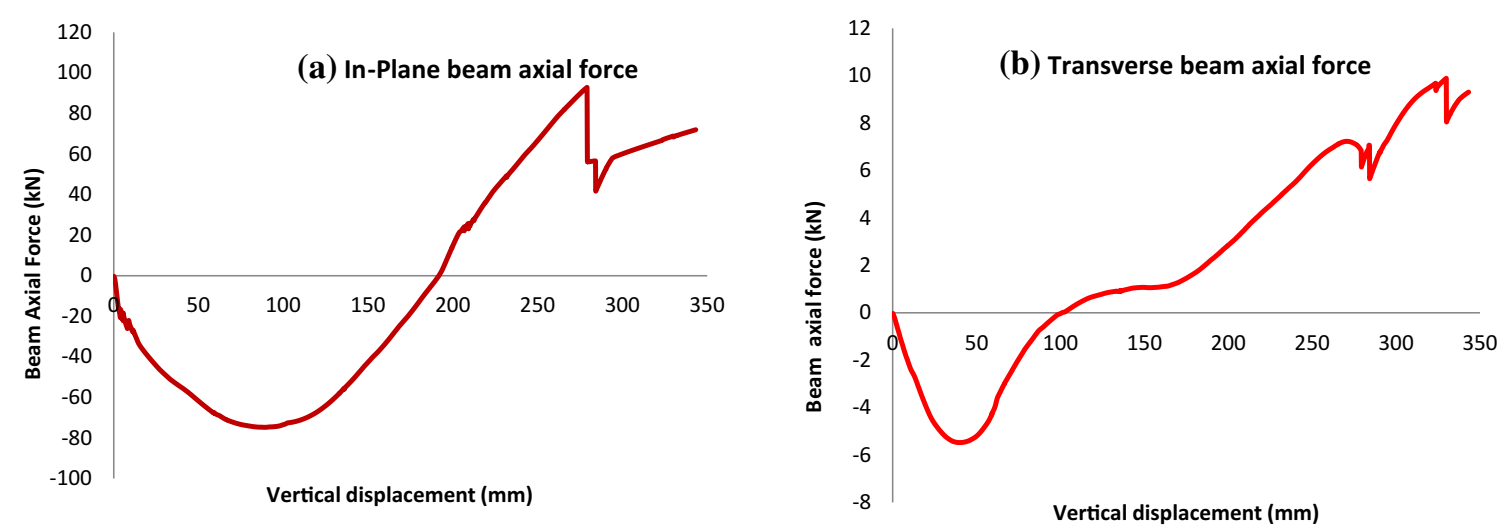

Fig. 23 Variation of beam axial forces versus vertical displacement of middle joint. a In-plane beam axial force. b Transverse beam axial force. 


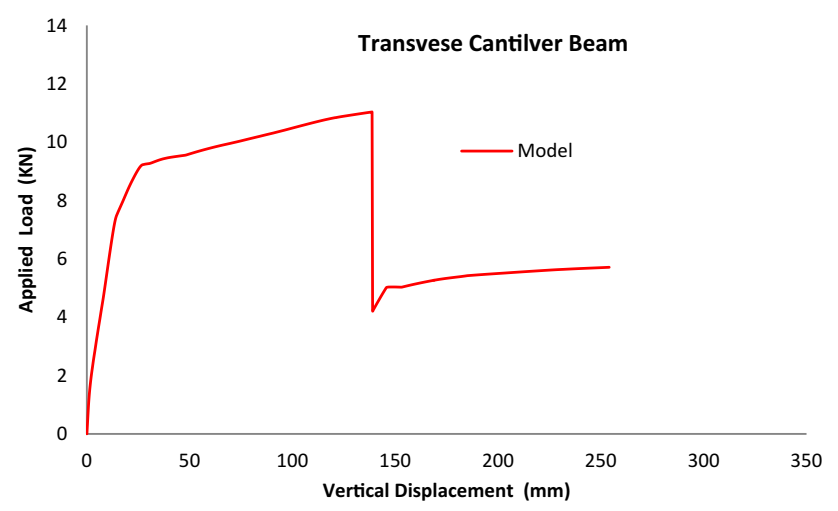

Fig. 24 Numerical load-deflection curve of the transverse beam as a cantilever beam.

forces are developed and they increase up to the end of the test. The development of tensile forces demonstrates the catenary mechanism in the sub-assemblage.

Numerical results in Fig. 23b confirm that the amount of axial force in the transverse beam is significantly small during loading. The compressive axial forces of the transverse beam increase during the initial stages of the loading process, up to a vertical displacement of $32 \mathrm{~mm}$. At greater displacements, the axial compressive forces start to decrease, and at a vertical displacement of $52 \mathrm{~mm}$, the forces change from compression to tension. These tension forces continue to increase up to the end of the test. However, in spite of the same trends in the development of axial forces in both the main and transverse beams, the dominant mechanisms are different. The main resistance mechanism in the transverse beam is flexural action, whereas resistance in the main beams is based on different mechanisms, such as flexural, arching and catenary actions during the different steps of analysis.

To evaluate the role of the transverse beam in the redistribution of unbalanced loads under the column removal scenario, a separate analytical model of the transverse beam that simulates cantilever behavior was constructed and analyzed under free end loading. To improve the simulation and consider the effects of the middle column, the in-plane rotation of the free end is restricted and only its vertical displacement is allowed. The resulting load-displacement curve (Fig. 24) shows the considerable role played by the transverse beam in enhancing flexural action. Furthermore, the curve shows that the flexural capacity of the transverse beam increases up to a vertical displacement of $140 \mathrm{~mm}$. This justifies the greater resistance and also the gentle drop in bearing capacity of the $3 \mathrm{D}$ sub-assemblage in comparison to the planar specimen.

Generally, the simulation results indicate that the introduced analytical model, along with the joint model and zero length elements, provide a reliable prediction of the structural behaviors of RC sub-assemblages under a column removal scenario. The introduced framework can be used to analyze RC frames with different geometric and boundary conditions and can also be used for 3D frames.

\subsection{Parametric Study}

To investigate the effects of column locations and beam geometry on the behavior of the substructure in the column removal scenario, six models were introduced and analyzed. The new models have characteristics similar to those of an IMF specimen (N1) while considering transverse beams (N2), different removed column locations (N3) and different beam geometry and reinforcement (N4-N6). The details of the models were presented in Table 4.

In this study, the effects of transverse beams on the progressive collapse behavior of exterior frames were investigated. Interior columns have some probability of being targeted by a terrorist attacks or damage in a car accidents resulting in losing their load carrying capacity. Therefore, model N3 with two transverse frames for modeling interior column removal was analyzed. Figure 25 a shows the loaddisplacement results of models N1-N3. The consideration of transverse frames significantly enhances the bearing capacity of the structure. It should be noted that, interior columns have larger gravitational loads. Therefore, the enhancement in load capacity of interior frames in comparison to exterior frames should be compared with their initial gravity loads in the removed columns.

The publication UFC 4-023-03 (2010) "Design of buildings to resists progressive collapse” increased gravitational loads for floor areas above a removed column. This code applies the following increased gravity load combination to those bays immediately adjacent to the removed element and at all floors above the removed element:

$$
G_{N}=\Omega_{N}[(0.9 \text { or } 1.2) D+(0.5 L \text { or } 0.2 S)]
$$

where $G_{N}$ is the increased gravity loads for the nonlinear static analysis, D the Dead load $\left(\mathrm{kN} / \mathrm{m}^{2}\right)$, L the live load $\left(\mathrm{kN} / \mathrm{m}^{2}\right)$, S the snow load $\left(\mathrm{kN} / \mathrm{m}^{2}\right)$, and $\Omega_{N}$ the dynamic increase factor for calculating deformation-controlled and force-controlled actions for nonlinear static analysis.

Table 5 shows the CAA and CA capacity of the N2 and N3 models and the increased gravity loads for removed columns in these models. As seen, despite greater capacity in model N3, it has not resulted in a conservative safety factor for progressive collapse, especially in the CA stage.

Two optional methods for increasing progressive collapse resistance are: increasing the beam heights and adding longitudinal reinforcement to the exterior beams. In this study two models, N5 and N6, with 700 and $600 \mathrm{~mm}$ beam heights, respectively, were analyzed. The details of these models were identical to those of the IMF specimen (N1), which had a transverse beam; however, there were differences in the beam heights and modifying longitudinal reinforcement for satisfying minimum reinforcement percentages in the ACI code.

Based on the investigation performed by $\mathrm{Yu}$ and Tan (2014), half of minimum reinforcements in the N4 model, which were defined by ACI 318, were added to the midheights of the exterior beams. In Fig. 25b, the load displacement response of N2, N4, N5 and N6 were plotted. Increasing the beam height significantly increases the 


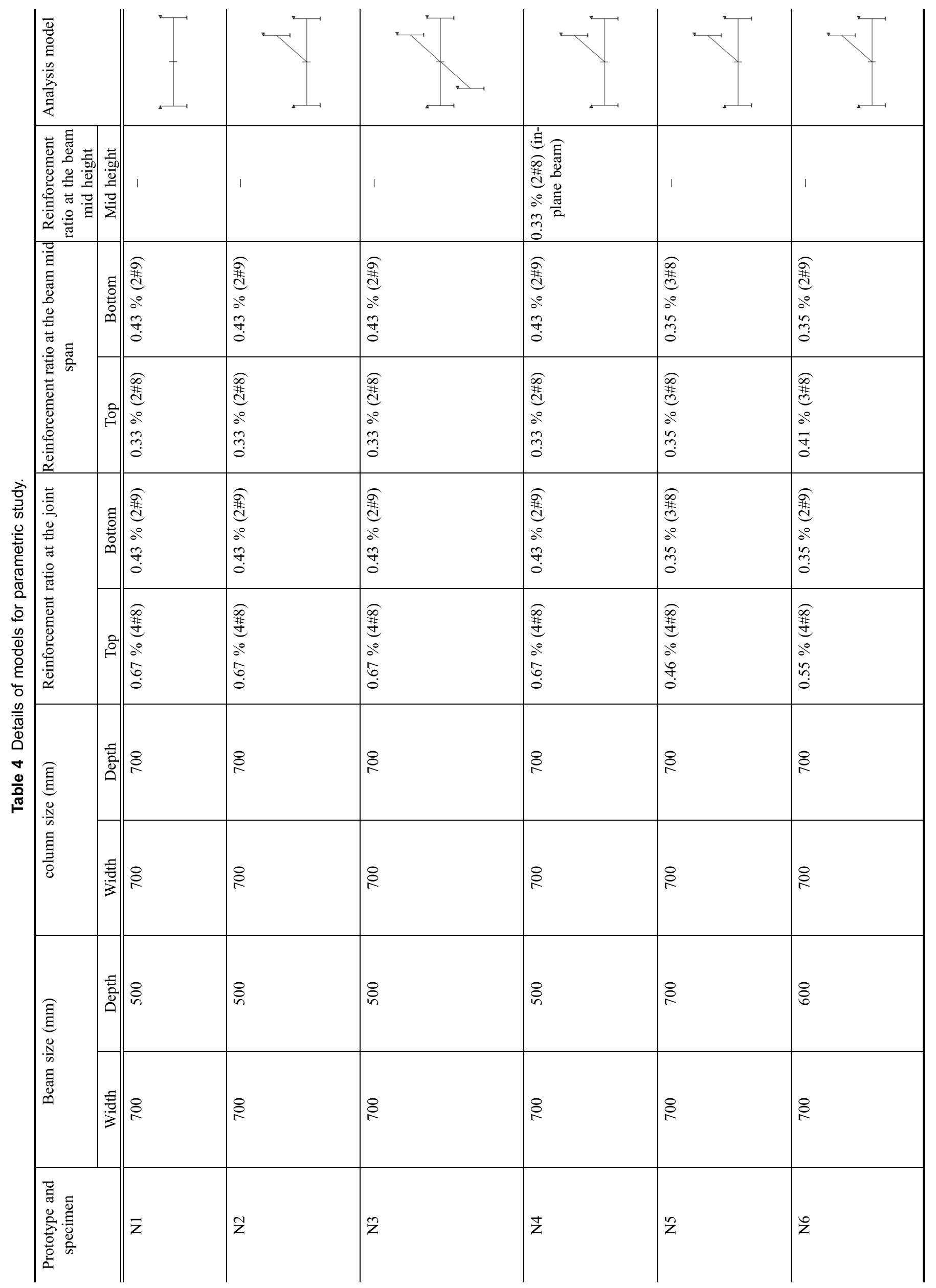



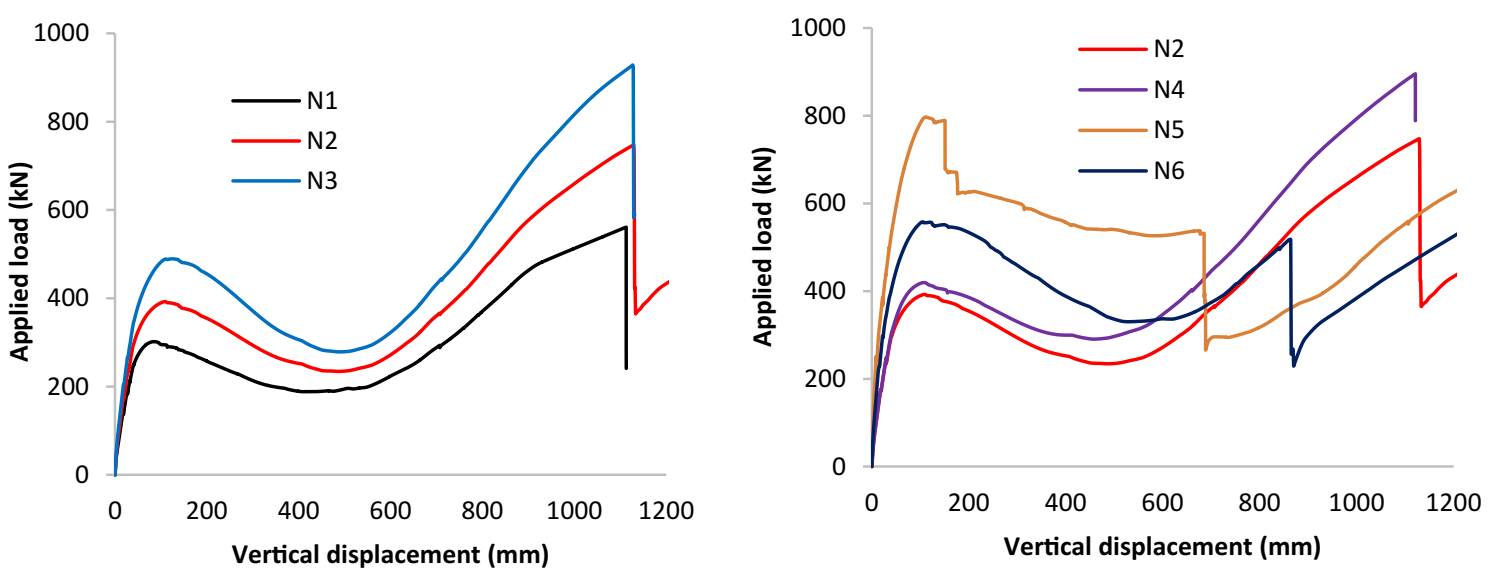

Fig. 25 Effect of removed column location and beam section details on load-displacement curve.

Table 5 Progressive collapse strength and proportions to gravity loads of the removed column.

\begin{tabular}{c|c|c|c|c|c}
\hline Model & CAA strength $(\mathrm{kN})$ & CA strength $(\mathrm{kN})$ & Gravity load $\left(\mathrm{G}_{\mathrm{N}}\right)(\mathrm{kN})$ & $\mathrm{CAA}_{\mathrm{G}}$ & $\mathrm{G}_{\mathrm{N}}$ \\
\hline \hline $\mathrm{N} 2$ & 393 & 747 & 254 & 1.54 & 2.94 \\
\hline $\mathrm{N} 3$ & 490 & 924 & 507 & 0.97 & 1.82 \\
\hline
\end{tabular}

flexural and arch action resistance of the beams. However, the deeper beams lead to the fracture of longitudinal bars in the early stages of loading and consequently decrease the catenary action of the sub-assemblage. However, adding longitudinal reinforcement in the mid heights of the beam section also has little effect on flexural and arching actions. Instead, it improves the tensile resistance of the beam and thereupon increases catenary action of the substructure.

\section{Conclusions}

This study has presented experimental and numerical evaluations of RC sub-assemblages under the column removal scenario, with the aim of considering the effects of transverse beams and frames. Additionally, various resistance mechanisms against progressive collapse and the failure modes of RC members were also discussed. To achieve these goals, a 3D RC sub-assemblage including a transverse beam was exposed to monotonic downward displacement of the middle joint and the results are compared to a corresponding planar specimen. The tested sub-assemblages were part of an exterior frame in a 10-story building. In addition, a numerical investigation of both 3D and planar assemblies was also performed. The results of this study are outlined below.

- Experimental observations demonstrate that the arching and catenary actions could not develop in a transverse beam due to insufficient axial restraint. In contrast, the flexural capacity of the sub-assemblage is enhanced because of the additional flexural resistance of the third beam. In addition, comparison of the $3 \mathrm{D}$ and planar specimens demonstrated that the transverse beam helps to achieve a more symmetric and ductile behavior within the main beams.

- The results also show that the enhancement of structural resistance due to the arching action, in comparison to flexural action, is about $19 \%$. In addition, ultimate arching action is achieved at a vertical displacement equal to half the beam depth. The change in the axial forces from compression to tension starts at a displacement equal to the beam depth at the middle joint. The enhancement due to catenary capacity in the end of the test is about 1.4 times the arching capacity. Similar conclusions have been reported in previous research, but with some differences in ratios.

- A numerical study of the sub-assemblages indicated that the proposed macro-based model could provide a reliable foundation for the analysis of progressive collapse in $\mathrm{RC}$ frames. Different resistance mechanisms in RC assemblies under the column removal scenario could be simulated using the proposed framework.

- Increases in beam heights significantly increase the beam action mechanisms of the substructures. However, an increase in beam heights leads to fracturing of longitudinal bars at early stages of loading and consequently decreases the catenary action of the sub-assemblage.

- Adding longitudinal reinforcement to the mid-height sections of the beam increases the catenary action of the substructure considerably without a change in model behavior at other stages.

Although an extensive study has been performed to understand the collapse behavior of RC assemblies, some aspects need further evaluation. The role of slabs in structural behavior and a consideration of the effects of an initial incident that triggers the progressive collapse are the main areas that should be addressed in the near future. 


\section{Open Access}

This article is distributed under the terms of the Creative Commons Attribution 4.0 International License (http:// creativecommons.org/licenses/by/4.0/), which permits unrestricted use, distribution, and reproduction in any medium, provided you give appropriate credit to the original author(s) and the source, provide a link to the Creative Commons license, and indicate if changes were made.

\section{References}

ACI Committee 318-02. (2002). Building Code Requirements for Structural Concrete (ACI 318-02) and Commentary (318R-02). Farmington Hills, MI: American Concrete Institute.

Ahmadi, R., Rashidian, O., Abbasnia, R., Mohajeri Nav, F., \& Yousefi, N. (2016). Experimental and numerical evaluation of progressive collapse behavior in scaled RC beam-column sub-assemblage. Shock and Vibration,. doi:10.1155/ 2016/3748435.

Altoonash, A. (2004). Simulation and damage models for performance assessment of reinforced concrete beam-column joints. Ph.D. Dissertation, Standford University, Stanford, CA.

Bao, Y. H., \& Kunnath, S. K. (2010). Simplified progressive collapse simulation of RC frame-wall structures. Engineering Structures, 32(10), 3153-3162.

Bao, Y. H., Kunnath, S. K., El-Tawil, S., \& Lew, H. S. (2008). Macro-model based simulation of progressive collapse: RC frame structures. Journal of Structural Engineering, 134(7), 1079-1091.

Bao, Y. H., Lew, H. S., \& Kunnath, S. K. (2014). Modeling of reinforced concrete assemblies under a column removal scenario. Journal of Structural Engineering, 140(1), 04013026.

Bentz, E. C. (2000). Membrane-2000: Reinforced Concrete Membrane Analysis using the Modified Compression Field Theory. Toronto, Canada: University of Toronto.

Choi, H., \& Kim, J. (2011). Progressive collapse-resisting capacity of RC beam-column sub-assemblage. Magazine of Concrete Research, 63(4), 297-310.

Department of Defense (DoD) Unified facilities criteria (UFC). (2010). Design of buildings to resist progressive collapse. UFC 4-023-03, U.S. DoD.

Farhang Vesali, N., Valipour, H., Samali, B., \& Foster, S. (2013). Development of arching action in longitudinallyrestrained reinforced concrete beams. Construction and Building Materials, 47, 7-19.

Harris, H. G., \& Sabins, G. M. (1999). Structural modeling and experimental technique (2nd ed.). Boca Raton, FL: CRC Press.

Jian, H., \& Zheng, Y. (2014). Simplified models of progressive collapse response and progressive collapse-resisting capacity curve of RC beam-column substructures. Journal of Performance of Constructed Facilities, 28(4), 04014008.
Kim, J., \& Choi, H. (2015). Monotonic loading tests of RC beam-column subassemblage strengthened to prevent progressive collapse. International Journal of Concrete Structures and Materials, 9(4), 401-413.

Lew, H. S., Bao, Y. H., Main, J. A., Pujol, S., \& Sozen, M. A. (2014). Experimental study of reinforced concrete assemblies under column removal scenario. ACI Structural Journal, 111(4), 881-892.

Lew, H. S., Bao, Y. H., Sadek, F., Main, J. A., Pujol, S., \& Sozen, M. A. (2011). An experimental and computational study of reinforced concrete assemblies under a column removal scenario. NIST Technical Note 1720.

Lowes, L. N., \& Altoontash, A. (2003). Modeling reinforcedconcrete beam-column joints subjected to cyclic loading. Journal of Structural Engineering, 129(12), 1686-1697.

McKenna F et al. (2007). Open system for earthquake engineering simulation (OpenSees). http://www.opensees. berkeley.edu. PEER. Berkeley, CA: University of California.

Qian, K., \& Li, B. (2012a). Dynamic performance of reinforced concrete beam-column substructures under the scenario of the loss of corner column-Experimental results. Engineering Structures, 42, 154-167.

Qian, K., \& Li, B. (2012b). Slab effects on the response of reinforced concrete substructures after loss of corner column. ACI Structural Journal, 109(6), 845-856.

Qian, K., \& Li, B. (2015). Quantification of slab influences on the dynamic performance of $\mathrm{RC}$ frames against progressive collapse. ASCE Journal of Performance of Constructed Facilities, 29(1), 04014025.

Qian, K., Li, B., \& Ma, J. X. (2014). Load-carrying mechanism to resist progressive collapse of RC buildings. Journal of Structural Engineering (ASCE), 141(2), 04014107.

Qian, K., Li, B., \& Zhang, Z. W. (2015). Testing and Simulation of 3D Effects on Progressive Collapse Resistance of RC Buildings. Magazine of Concrete Research, 67(4), 163-178.

Sasani, M., Bazan, M., \& Sagiroglu, S. (2007). Experimental and analytical progressive collapse evaluation of an actual reinforced concrete structure. ACI Structural Journal, 104(6), 731-739.

Sasani, M., Kazemi, A., Sagiroglu, S., \& Forest, S. (2011a). Progressive collapse resistance of an actual 11-story structure subjected to severe initial damage. Journal of Structural Engineering, 137(9), 893-902.

Sasani, M., \& Kropelnicki, J. (2008). Progressive collapse analysis of an RC structure. The Structural Design of Tall and Special Buildings, 17(4), 757-771.

Sasani, M., \& Sagiroglu, S. (2008). Progressive collapse resistance of hotel San Diego. Journal of Structural Engineering, 134(3), 478-488.

Sasani, M., Werner, A., \& Kazemi, A. (2011b). Bar fracture modeling in progressive collapse analysis of reinforced concrete structures. Engineering Structures, 33, 401-409.

Su, Y. P., Tian, Y., \& Song, X. S. (2009). Progressive collapse resistance of axially-restrained frame beams. ACI Structural Journal, 106(5), 600-607. 
Tsai, M. H., \& Huang, T. C. (2015). Collapse-resistant performance of RC beam-column sub-assemblages with varied section depth and stirrup spacing. The Structural Design of Tall and Special Buildings, 24(8), 555-570.

Vecchio, F. J., \& Collins, M. P. (1986). The modified compression field theory for reinforced concrete elements subjected to shear. ACI Structural Journal, 83(2), 219-231.

Yi, W. J., He, Q. F., Xiao, Y., \& Kunnath, S. K. (2008). Experimental study on progressive collapse-resistant behavior of reinforced concrete frame structures. ACI Structural Journal, 105(4), 433-439.

Yu, J., \& Tan, K. H. (2011). Experimental and numerical investigation on progressive collapse resistance of reinforced concrete beam column sub-assemblages. Engineering Structures, 55, 90-106.

Yu, J., \& Tan, K. H. (2013a). Experimental and numerical investigation on progressive collapse resistance of reinforced concrete beam column sub-assemblages. Engineering Structures, 55, 90-106.

Yu, J., \& Tan, K. H. (2013b). Structural behaviour of reinforced concrete beam-column sub-assemblages under a middle column removal scenario. Journal of Structural Engineering, 139(2), 233-250.

Yu, J., \& Tan, K. H. (2014). Special detailing techniques to improve structural resistance against progressive collapse. Journal of Structural Engineering, 140(3), 04013077. 